\title{
THE USE OF MUSIC THERAPY STRATEGIES TO ENHANCE THE GENERAL MILIEU IN A REHABILITATION CENTRE.
}

\section{BY}

\section{XINXIN LIU}

\begin{abstract}
A thesis
submitted to the Victoria University of Wellington in fulfillment of the requirements for the degree of Master of Music Therapy
\end{abstract}

Victoria University of Wellington 2011 


\begin{abstract}
This research focused on how music therapy strategies could be used to improve the milieu in a rehabilitation centre in a New Zealand city. Residents in the rehabilitation centre had difficulty interacting with each other. I planned to use a Community Music Therapy approach to address residents' social needs. The research methodology was Action Research which involves the study of one's own practice. Cycles of learning led to the introduction of more 'open' groups and the use of the 'sharing concert' as a vehicle for promoting interaction between residents, staff, and family members, and staff and children at an early childhood centre. I examined the group dynamics, encouraged residents to move from small groups to bigger group or even open groups, and began to challenge them to take responsibility for individual tasks for their own and others' benefit. Through interactive music making, the residents improved understanding about conversation courtesy; their motivation for active participation increased as they developed a sense of togetherness, and appreciation for their community. They enjoyed interacting with the wider community also, and had the wish to 'branch out'. Further, the action research changed my understanding and leadership style: I learnt to gradually move from an aesthetic focus and into a supportive role as residents prepared for "their own concert".
\end{abstract}




\section{ACKNOWLEDGEMENT}

I would like to acknowledge and thank the following people who helped me to complete this thesis:

My research supervisor Dr Daphne Rickson who offered me enormous support and guidance;

The staff members and residents in the rehabilitation centre, especially the interview participants;

The CEO who permitted me to do research in the rehabilitation, and my supervising manager who gave me support during my student placement;

Fellow student Coco Kho who helped organizing the concerts;

Louis Liu who gave me continuous support,

and Jesus Christ.

This research was approved by Massey University Human Ethics Committee (HEC:

Southern A Application 10/53) on Tuesday $15^{\text {th }}$ of June, 2010. The research was carried under Massey University's Code of Ethical Conduct for Research Involving Human Subjects (Massey University, 2010). 


\section{TABLE OF CONTENTS}

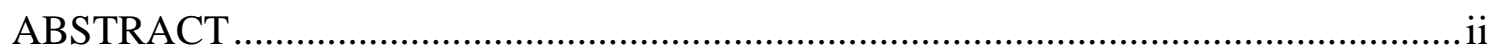

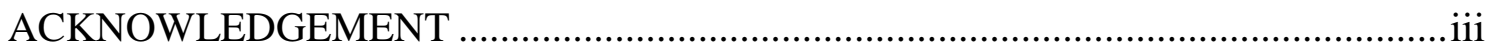

TABLE OF CONTENTS ............................................................................................. iv

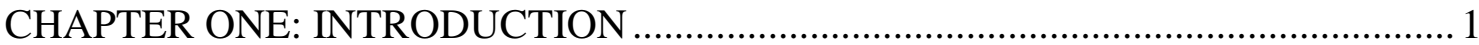

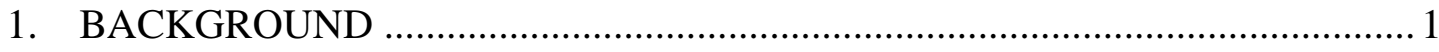

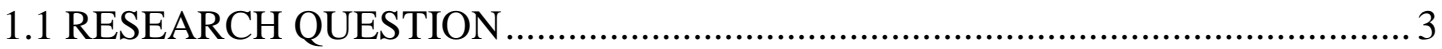

1.2 AIMS OF THE THESIS ........................................................................... 3

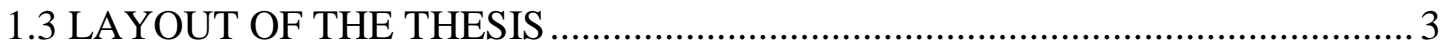

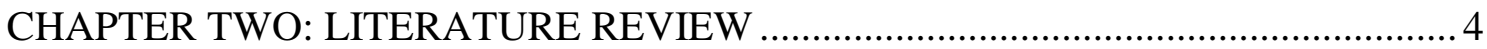

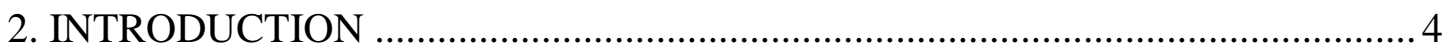

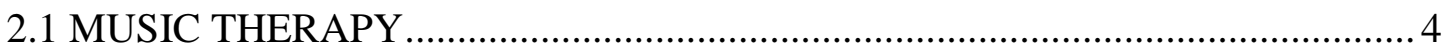

2.2 COMMUNITY MUSIC THERAPY …………………….............................. 4

2.3 GROUP MUSIC THERAPY ………………………………………….....

2.4 MUSIC THERAPY FOR PEOPLE WHO HAVE PHYSICAL OR

NEUROLOGICAL DISABILITIES ................................................................... 8

2.5 COMMUNITY MUSIC THERAPY AND ACTION RESEARCH …………….... 9

2.6 SUMMARY OF LITERATURE REVIEW ……………………………....... 10

CHAPTER THREE: THEORETICAL PERSPECTIVES AND METHODS .................. 11

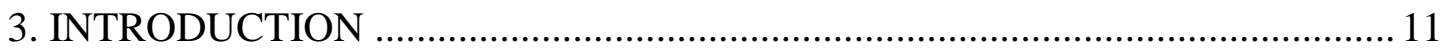

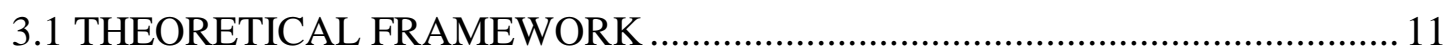

3.2 METHODOLOGY-ACTION RESEARCH ........................................................ 12

3.3 ACTION RESEARCH-DESIGN AND METHODS ........................................... 13

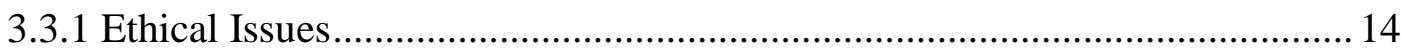

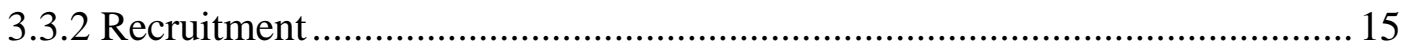

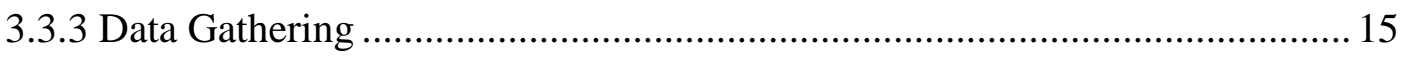

3.3.4 Data Analysis ………………………………………………………. 16

3.3.5 Researcher's Personal Position ..................................................................... 19

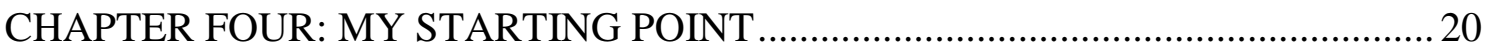

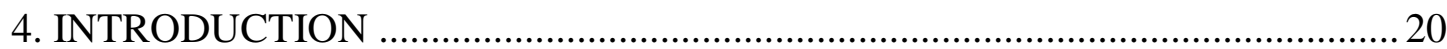

4.1. CATEGORIES FROM THE FIRST CONCERT …………………………...... 20

4.2 SUMMARY OF THE FIRST CONCERT ....................................................... 25

4.3 CATEGORIES FROM THE FIRST INTERVIEW …………………………….... 26

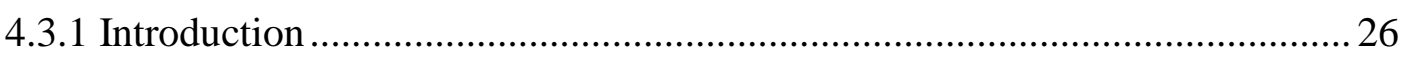

4.3.2 Categories from the First Interviews......................................................... 26

4.3.3 Expansion on the Categories for the First Interviews ……………………..... 26

4.4 SUMMARY OF THE FIRST INTERVIEW ………………………………...... 29

4.5 SUMMARY OF THE STARTING POINT SECTION ………............................ 30

CHAPTER FIVE: FINDING FROM ACTION RESEARCH CYCLES............................ 31

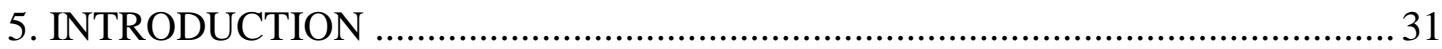

5.1 CYCLE 1: PREPARTION FOR ECC CONCERT …………………………......... 31

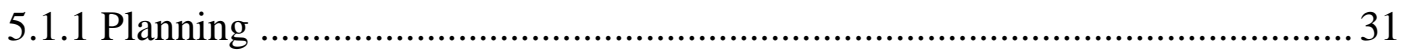

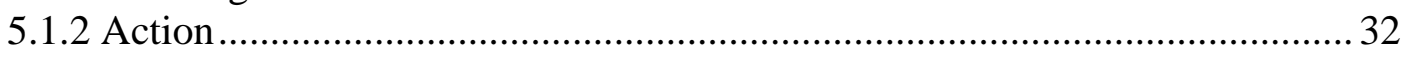

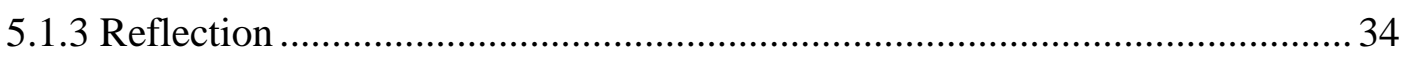

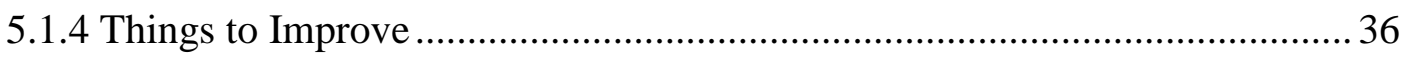

5.2 CYCLE 2: PRACTICE FOR ECC CONCERT (SECOND CONCERT) ............... 37

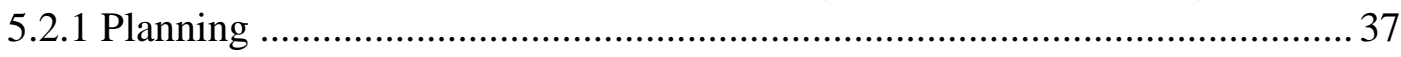

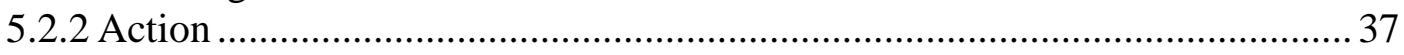




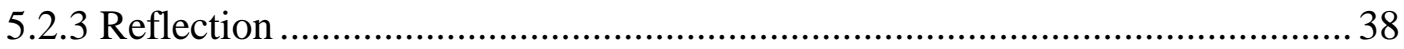

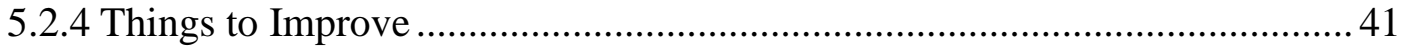

5.3 CYCLE 3: ECC CONCERT (THE SECOND CONCERT) ….......................... 42

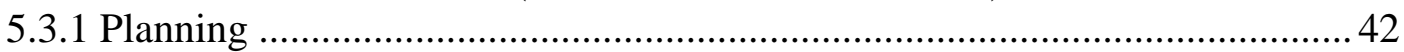

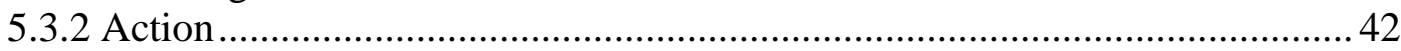

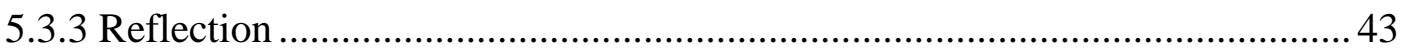

5.3.4 Things to Improve ..................................................................................... 44

5.4 CYCLE 4: PREPARING FOR THE PRE-CHRISTMAS CONCERT, AND RE-

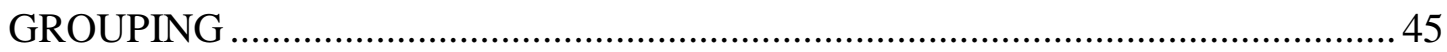

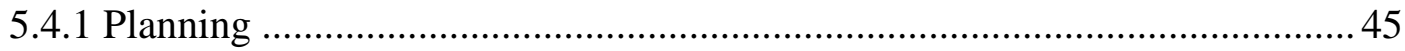

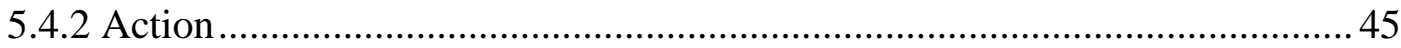

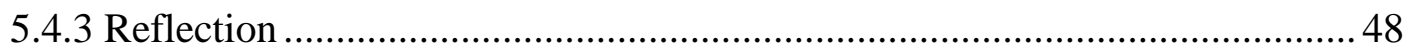

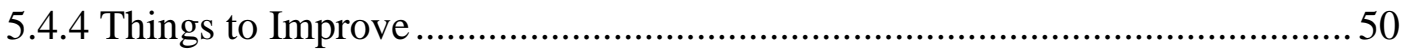

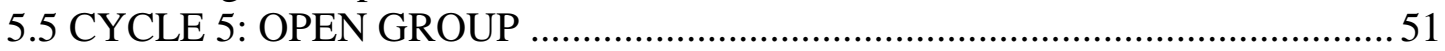

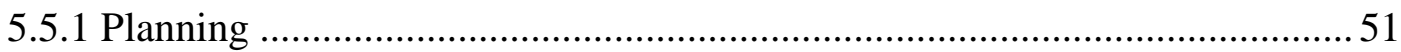

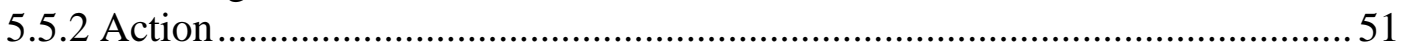

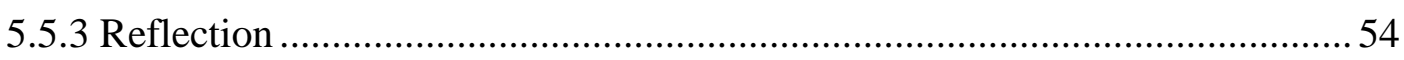

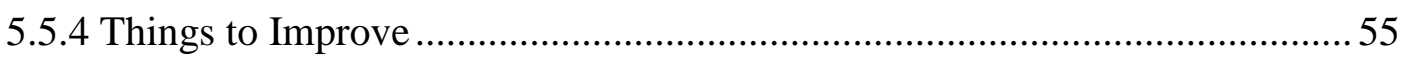

5.6 CYCLE 6: PRE-CHRISTMAS CONCERT (THE THIRD CONCERT) ..............56

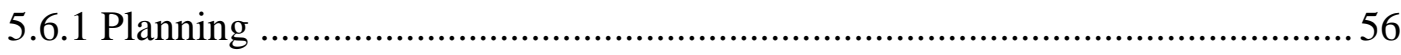

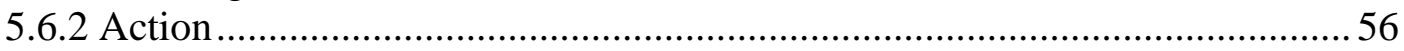

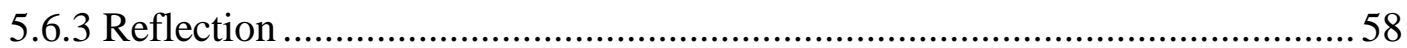

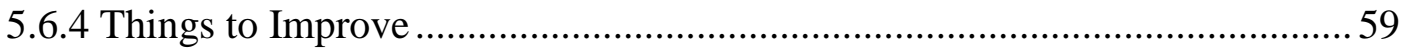

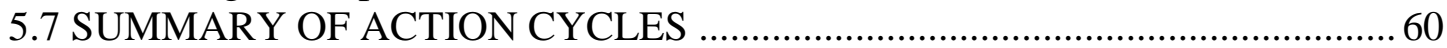

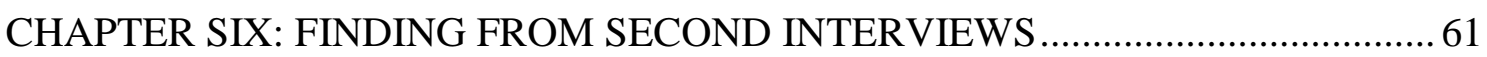

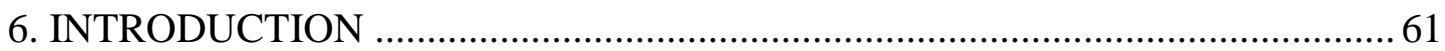

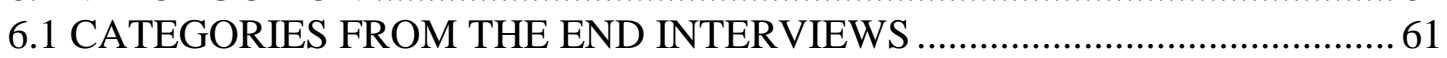

6.2 EXPASION ONCATEGORIES FROM THE SECOND INTERVIEW ............... 62

6.3 SUMMARY OF FINDINGS FROM THE SECOND INTERVIEW ...................6 65

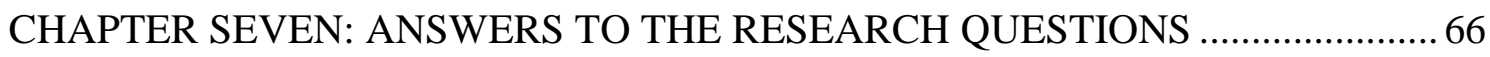

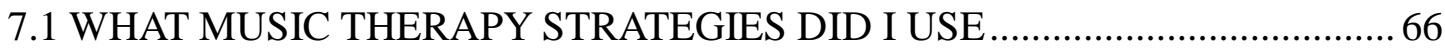

7.2 HOW DID THE MUSIC THERAPY STRATEGIES IMPROVE THE MILIEU 66

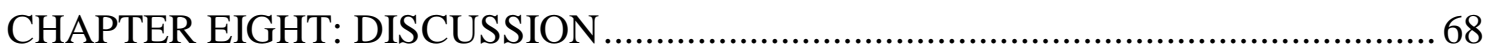

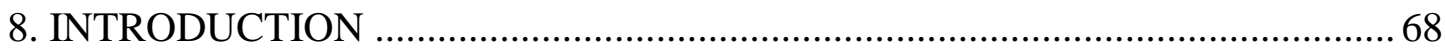

8.1 DISCUSSION OF FINDING IN RELATION TO THE LITERATURE.............. 68

8.1.1Music Therapy Strategies Empowered the Institutionalised Adults ................6 68

8.1.2 Open Groups Can Help the Residents to Adapt To Changes in the Milieu ... 70

8.1.3 Group Dynamics Was an Important Part of Working with Music Therapy

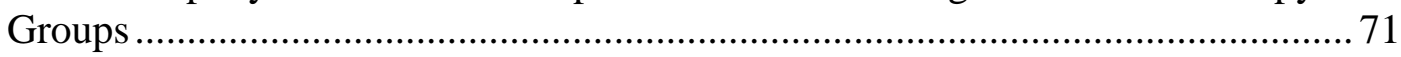

8.1.4 Music Therapy Strategies Improved Sense of Belonging:.......................... 72

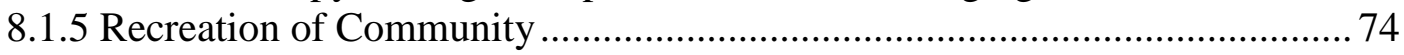

8.1.6 Traditional or Community Music Therapy …................................................. 76

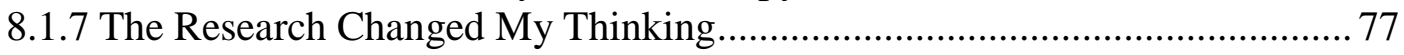

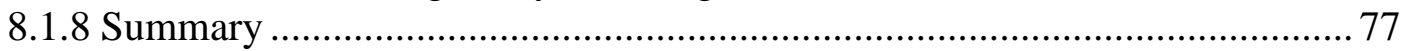

8.2 METHODOLOGICAL CONSIDERATIONS …............................................... 78

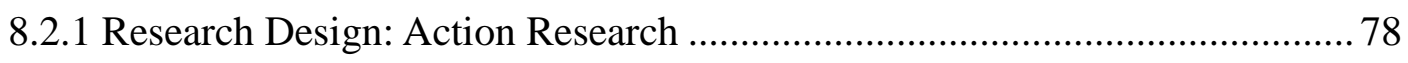

8.2.2 Limitation On Data Collection: Interview Participants ................................ 78

8.2.3 Limitation on Data Analysis: Thematic Analysis ......................................... 78

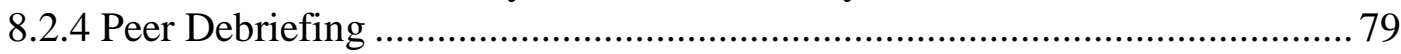

8.2.5 Re-define the Word Milieu during the Research........................................ 79 


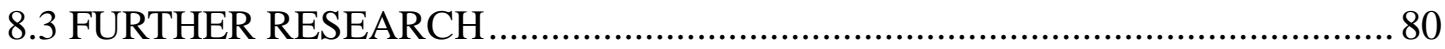

8.3.1 Data Collection: Systematic Observation and Reflection ................................. 80

8.3.2"Real Life Music" Re-wires the Brain ............................................................. 80

8.3.3 Milieu Music Might Be an Interesting Topic in Further Research .................. 81

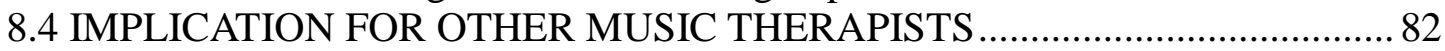

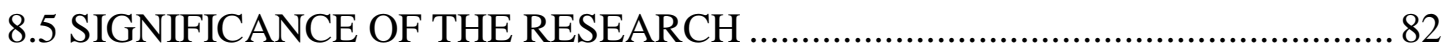

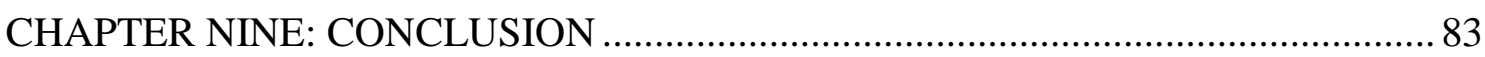

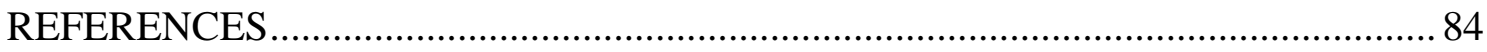

Appendix 1 Advertisement to staff members.............................................................90

Appendix 2: Information sheet for staff members .................................................... 91

Appendix 3: Consent form for staff members........................................................... 94

Appendix 4: Interview guideline for staff interviewees..............................................96

Appendix 5: Information sheet for residents........................................................... 97

Appendix 6: Consent form for residents …………………………………………....99

Appendix 7: Interview guidelines for resident interviewees..................................... 101

Appendix 8: Authority for the release of transcripts form for staff and resident

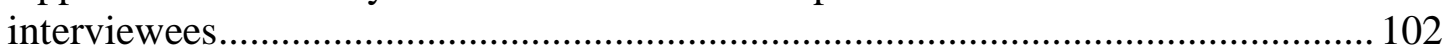

Appendix 9: Example of Observation and Reflection ................................................. 103

Appendix: 10: Examples of Interview Transcripts .................................................. 104

Appendix 11: Examples of analyzing Observation and Reflection ............................ 105

Appendix 12: Examples of analyzing Interview Transcripts ..................................... 107 


\section{CHAPTER ONE: INTRODUCTION}

\section{BACKGROUND}

I am a Music Therapy student conducting research in a rehabilitation centre as partial fulfillment of my study.

\section{The Rehabilitation Centre}

The rehabilitation centre is not medically based, in terms of stages of health care, it lies between rehabilitation and community stages of health care (O'Grady \& McFerran, 2007). The focus of the centre is maintaining residents' personal health, quality of life and wellbeing; helping them to gain independence and preparing them for re-entering society.

\section{The Residents}

There are twenty-five clients, aged from thirty to sixty years old, living in the centre and additional clients visit the centre during daytime. The clients will be generally called residents in this research. The residents have physical disabilities due to various congenital and neurological conditions. They also have social and emotional difficulties. Staff have identified that although the residents live together, they have difficulties interacting with and supporting each other. These difficulties may be due to a range of issues, including brain damage, chronic health issues and care received over time leading to a state of learned helplessness. Seligman (1975) defined learned helpless as an active learning process that prevents people from feeling self-mastering, The individuals who experience learned helplessness view outcomes as irrelevant to their own behaviour, therefore stop trying to do anything.

\section{The Need to Work in Context}

On my first visit to the centre, I felt like an outsider because the residents seemed to 
prefer engaging with the karaoke machine and television rather than music therapy sessions. I resonated strongly to what Mercedes Pavlicevic (2004b) wrote in the 'Community Music Therapy book' about feeling de-skilled when entering an existing community. Instead of working with the people individually, Pavlicevic joined the group and sang with them (Pavlicevic, 2004b). That was when I realised I should work in context and re-shape my skills in response to the moment (Pavlicevic, 2004).

\section{Music Therapy in the Rehabilitation Centre Prior to the Research}

During my first six months of clinical practice in the rehabilitation centre, I established rapport with the clients. I worked with their emotional, social and physical needs. I worked with them individually until they built up their music skills and confidence. I then worked with them in small closed groups and one large open group called the 'singing group'. I joined other group activities with music including a "girls can do anything" group in which we made music instruments together; and a "travel the world" group in which we experienced music and food from different countries. Some residents chose music as a priority over other activities. The residents in the singing group performed a concert in August to staff members, guests and other residents. Staff members appreciated the input of the resident performers, and gave them positive feedback. Staff members also suggested a CD be put on at lunch time to help the residents control their food intake. The performers and audience from the concert began to plan another concert. It seemed as if there had been some change in the general milieu in the centre since music therapy started (see further information regarding my starting point, in Chapter Four).

\section{The Influence of Community Music Therapy Theory}

My practice involves traditional closed door music therapy practice as well as other music related activities according to the residents' needs. The latter is informed by Community Music Therapy. Mercedes Pavlicevic had a metaphor about Community Music Therapy: "music naturally radiates, like dropping a pebble in a pond and ... the waves of energy spread out in concentric circles" (Pavlicevic, 2004, p.16). Music naturally permeates walls, and attracts people. It is not designed for private enjoyment (Pavlicevic, 2004). Community music therapy goes beyond closed doors and into 
institutions and wider communities (Wood, 2004). Community music therapy can follow the client's need according to their health and well-being (O'Grady \& McFerran, 2007). However, community music therapy is a new term and little research has been done within this area especially with rehabilitation centres. As a music therapy student, I was interested to know how I can improve the general milieu in a rehabilitation centre by developing a practice based on Community Music Therapy.

\subsection{RESEARCH QUESTION}

What can I as a music therapy student do to improve my practice, and enhance the general milieu of a rehabilitation centre?

\subsection{AIMS OF THE THESIS}

1. I want to investigate how I can bring residents together and support their ability to work as a team, and thus to enhance the milieu of the centre.

2. I want to describe music therapy strategies that can be used to enhance the general milieu of a rehabilitation centre.

\subsection{LAYOUT OF THE THESIS}

Chapter Two is a review of the literature. Chapter Three details the theoretical perspectives and methodology. Chapter Four describes my starting point for the action research, and includes a description of the first concert, and findings from the first interviews. Chapter Five contains the findings from the six action cycles. Each cycle of learning informs the next. Chapter Six contains the findings from the second round of interviews. Chapter Seven contains the answer to the research question. Chapter Eight consists of the discussion to the research findings and relevant literatures. The thesis is summarized in Chapter Nine. 


\section{CHAPTER TWO: LITERATURE REVIEW}

\section{INTRODUCTION}

This chapter contains literature relating to Community Music Therapy; Group Music Therapy; Music Therapy for the people who have neurological or physical diseases; and Community Music Therapy and Action Research. This literature informed the design of this research. The literature that I encountered during the research, which shaped my thinking and my action, will be discussed later in Chapter Seven: Discussion.

\subsection{Music Therapy}

An early definition of Music Therapy is ' a systematic process of intervention wherein the therapist helps the client to promote health, using music experiences and the relationship that develops through them as dynamic forces of change' (Bruscia, 1998, p.20).

A more recent and local definition of music therapy is "the planned use of music to assist the healing and personal growth of people with identified emotional, intellectual, physical or social needs" (Music Therapy New Zealand, 2011).

Ruud (2004) divided music therapy into 'Traditional closed-door music therapy' and 'new music therapy or community music therapy'. Ruud stated that traditional music therapy is a treatment profession, focusing on therapist-client relationship and performing within medical or special education frames. Traditional music therapy is performed inside the institution and rarely makes link to the outside world (Ruud, 2004).

\subsection{Community Music Therapy}

It is now accepted that the concept of 'community' encompasses not only local communities but religious, work, family and cultural communities (Christopher, Madden \& Potts, 2007). The community of New Zealand consists of a great many communities or sub-communities, areas includes education, religion, ethnic, institution, 
culture, sports, social, arts, dissident, politic, service or fringe. These communities or sub-communities can form and reform in the process of working with or against each other (Department of Education, 1988). Community refers to the development of 'social bonds' that occur through emotional connections (Christopher, Madden \& Potts, 2007). A debate in 2002 accelerated the definition of Community music therapy.

Ansdell (2002) stated that in traditional music therapy, therapists' identity, boundary, goals and theories were essential. In contrast to the traditional music therapy, community music therapy resists a one-size-fits-all and follows the client needs, context and where the music leads (2003). His working definition of community music therapy is 'an approach to working musically with people in the context: acknowledging the social and cultural factors of client health, illness, relationships and music' (2002).

Bruscia (1998) and Ruud (2004) suggested music therapists to work with both clients and the community. Bruscia (1998) suggested Ecological Music Therapy. He postulated that the ecological group is the real community while therapy group is constructed as an 'artificial community'. Music therapists need to work with the community: to help clients to function in the community and the community to accept the clients.

Ruud (2004) also suggested that music therapists work with both the clients and the community, basing his argument on system theory. System Theory states that all entities are linked at various levels of reciprocal influences (Kenny, 1985, 1989, cited in Bruscia 1998). System theory suggests that regulation and control of movement within different types of systems are inter-related rather than cause-effect related (Kenny, 1989, as cited in Ruud, 2004). Each micro system, such as family, therapy group, and centres, are interrelated (Kenny \& Aigen, 2006). Music therapists also work with communities, focusing on systemic intervention: building networks, providing symbolic means for clients. Music is a social resource to heal and strengthen communities (Ruud, 2004).

Aasgaard worked within an ecological model of Music Therapy with consideration to the context and culture of his participants. He called his work 'music environmental therapy' and he defined it as 'a systematic process of using music to promote health in a specified environment, inside or outside of an institution' (1999: 34, cited in Ansdell, 2002). He works intimately with clients, but also in and with the milieu, aiming also to improve the institutional quality of life. He works flexibly with clients and his role 
involves writing songs with children, organizing a hospital band, and facilitating music life for patients and families (Ansdell, 2002).

\section{Community Music Therapy and Performance}

Ruud (2004) sates ill-health is a part of social systems, and is resulted by disempowerment and lack of social understanding. Music therapists shall use music to empower the clients and bridge the gap between individual and communities. Ruud (2004) argues that community music therapy should include performance with a systemic perspective.

Stige (2004) claimed that Community music therapy shall use performance as an interactive process and empowers the clients. Through the interactive process, performers are not just delivering the music, and the audience do not judge the quality of the performance. Instead, all the participants' values, choices and powers come to inter play. This improves the relationship between individual and community, thus empowers the individuals. Ansdell (2005) also states that community music therapy could involve participants performing for themselves. He suggests that performance can be therapeutically appropriate; performance focuses' on the process, and psychological satisfaction, it can also create relationships and connections between people and communities (Ansdell, 2005). Therefore, community music therapy can be further defined as the reflexive use of performance based music therapy within a systemic perspective (Ansdell, 2005).

\section{Community and Continuum}

Community Music Therapy fits into the current social model of disability (Pavlicevic \& Ansdell, 2004). Patients have various needs as they move from acute illness and crisis, to reintegrate into their communities. Traditional music therapy only works with clients at the illness and crisis stage of health-care, but Community Music Therapy follows along the health continuum, depending on the context (O'Grady\& McFerran, 2007). Some music therapists acknowledged that patients have limited opportunities to pursue their interest in music once they leave the music therapy rooms, and that there is a need 
for the clients to continue to use their music in an ongoing way to maximise well-being (O’Grady\& McFerran, 2007). In addition, Ansdell (2002) suggested community music therapy covers across traditional music therapy and community music making, and therapists shall work with both the clients and the community.

Wood (2004) suggested carrying out Community Music Therapy practice based on the traditional music therapy. In traditional music therapy clinical practice, some music therapists helped the clients to progress from individual to group music therapy sessions. In the Nordoff and Robbins model for example, children gained skills in individual music therapy, which later enabled them to participate in group work (Wood, 2004). Community Music Therapy work can build on the traditional music therapy sessions and can be carried out in a three-stage program: individual sessions; small musical groups and music workshops; before participants join the wider community (Wood, 2004).

\subsection{GROUP MUSIC THERAPY}

A group is more than just a collection of people (Levi, 2011). The group identifies it different from others. The group members interact and connect with each other, and share their values, ideas, and beliefs about the world. Therefore, members identify "us" as a group that is different from "them"; and they change the ways of viewing the world (Levi, 2011).

There are many advantages to group work. Group promotes sense of belonging. People with disability are often socially isolated, and being in groups can improve their sense of belonging and can motivate them to achieve a goal together (Geldard \& Geldard, 2001). In a group, the common needs of people can be addressed, such as music interest, physical rehabilitation, improved confidence, and consideration of others (Wheeler, 2005). Yalom (1985) described eleven therapeutic factors of groups: instillation of hope, universality, imparting of information, altruism, the corrective recapitulation of the primary family group; development of socializing techniques; imitative behaviour; interpersonal learning; group cohesiveness; catharsis; and existential factors. 
Group promotes behavioural or social change. Group members respond to the way the other members behave, by making changes in their own behaviour (Geldard \& Geldard, 2001). Group work can parallel some of the processes that occur in the wider society. Lewin( 1951, cited in Levi, 2011) was concerned about social change. He believed that changing the behavior of a group is easier than changing the behavior of an individual (Levi, 2011). If an individual changed his behaviour and then returned to daily life, he is likely to be influenced by the environment and reverse the changed behaviour. In contrast, if a group changed its behaviour, the group will continue to reinforce or stabilize the behavioural change in its members. However, the success of small group does not necessarily lead to success of change when the people come back to the environment. Small groups might have strong cohesiveness which prevents them from interacting outside of the group. Groups need to be open to the environment to adapt to changes (Jacobs \& Spradlin, 1974).

\subsection{MUSIC THERAPY FOR PEOPLE WHO HAVE PHYSICAL OR NEUROLOGICAL DISABILITIES}

Altenmuller (2004) explained how music affects the brain. Music is perceived as sound and processed in both left and right hemispheres of the brain. On the other hand, the vibration of music is perceived as tactile stimulus. Music also elicits strong emotions, and activates different parts in the brain. Every person's music preference is different, therefore the 'music centres' in the brain are unique to everyone. In a recent review article, Johansson (2011) studied the effect of music therapy on brain plasticity in the stroke patient. He defined brain plasticity as the ability for human brain to adapt to environmental pressure including stroke. Music-supported motor training significantly improves cortical connection, brain activation and function (Altenmuller, 2009, cited in Johansson, 2011). Johansson's review also found that music listening activates many brain structures and has the effects on improving attention, verbal memory, and emotional adjustment in stroke patients. Baker and Tampline (2006) states that singing and talking share neural pathways and activates similar regions in the brain. More importantly, when speech regions in the brain are damaged, singing songs activates other brain regions to recover the speech function. Daveson (2008) suggested a client centred model for working with clients with brain injuries. The model focused on 
functional restoration, pyscho-social-emotional recovery and complementary strategies of neural music therapy.

There are various music therapy strategies to enhance neural and physical rehabilitation. In a Cochrane review, Thaut's (2007, cited in Bradt 2010) research indicated that rhythmic auditory stimulation synchronise motor movement and improves motor function in stroke patients. Clair, Pasiali \& LaGasse (2008) suggested using music accompaniments to provide rhythmic structure for the movement. They also suggested choosing music instrument for therapeutic potential to maximise physical movements, such as range of motion, strength, finger dexterity, and co-ordination. Wong (2004) also suggested using music instruments to improve sit balance and upper body motor skills. In addition, Wong suggested dancing and swinging to music can improve static balance.

Baker and Tampline (2006) stated that singing and talking share structured patterns of sound and neural-physical pathways for sound production. In speech recovering, music therapists can use melody to improve pitch variation; rhythm to improve stress; wind instruments to improve lung function and phonation; and singing to promote comprehension.

Baker and Tamplin (2006) stated that clients with neural damage may also have cognitive impairments including poor attention, poor short-term memory, impulsivity and poor tolerance towards others or undesired situations. The cognitive function can only be partially recovered after brain injury, so compensatory music therapy strategies needed to be used. A neural scientist Sacks (1998) states strategies like singing songs about tasks and sequence embeds sequence in brain damaged clients. Familiar music helps recall emotion, long term memory and identity in demented clients.

\subsection{COMMUNITY MUSIC THERAPY AND ACTION RESEARCH}

Action research changes knowledge within communities or even in society. It allows the participants to have their voice through critical feedback and ensures the rights of the participants who are otherwise disempowered in research, are upheld (Hunt, 2005). Mcniff \& Whitehead (2010) said that action research is a collaborative, co-creation of knowledge of practice. Rickson (2010b) involved participants in research in a highly collaborative way by using participatory action research to develop music therapy 
school consultation protocol. My research involves participants in a less collaborative way. In my research, I consult the participants for critical feedback to improve the researcher's practice. As both researcher and music therapist, I needed to be aware of my impact on the participants. Action research is about creating change, which is made together with the researcher and the participants. Role equality in action research can empower the participants (Mcniff \& Whitehead, 2010).

Action research is widely used in community development, social work, and healthcare research. Action research can be used in music therapy research because it can contribute to daily lives and inform other researchers and clinicians about the work, and it empowers people through giving them choices and allowing their feedback to influence the research. Action research can stimulate communication and democratic dialogue so that the participants gain a deeper understanding of how they can influence their own situation rather than learning from people who have more power than them (Hunt, 2005).

\subsection{SUMMARY OF LITERATURE REVIEW}

Community Music Therapy is a model that follows client need along all the stages of health care: from state of illness to the state of social re-integration, and works with clients in the social and cultural context. Community Music Therapy can emerge from the traditional music therapy, moving from individual sessions and group sessions, to music workshops and concerts. Group music therapy addresses common needs, encourages a sense of belonging, and promotes behavioural and social changes among its members. Community Music Therapy can be studied through Action Research, because both approaches focus on creating social changes and empowering the participants.

Further literature that was uncovered during the course of this action research has been incorporated into the discussion. 


\section{CHAPTER THREE: THEORETICAL PERSPECTIVES AND METHODS}

\section{INTRODUCTION}

This section contains three parts: Theoretical Framework; Methodology-Action Research; and Action Research-Design and Methods.

\subsection{THEORETICAL FRAMEWORK}

This study is informed by theories of constructionism and symbolic interactionism.

Constructionism suggests that meaningful reality is socially constructed. Culture is a source of human thoughts, and it teaches us how to see things and where to see things. Social life constructs the researcher's thoughts and the researcher constructs the meaning of the researched object. Researchers should therefore be aware of their social and cultural background, how that background contributes to the construction of meaning (Crotty, 1998). In this research I will be reflecting on my values and beliefs to uncover how I am impacting on the research.

Symbolic interactionism informs research relating to communication, interrelationship and community (Crotty, 1998). Symbolic interactionism assumes that human beings act according to the way they understand things, that meaning is generated from social interaction, and that meaning is interpreted by the person who encounters things (Crotty, 1998). Thus it is anticipated that music making together will help the participants in this study to generate new meanings about their communal situation (Levi, 2011). 


\subsection{METHODOLOGY-ACTION RESEARCH}

Bruscia (1995) defines research as a systematic, self-monitored inquiry which leads to a discovery or new insight which, when documented and disseminated, contributes to or modifies existing knowledge or practice. All research has three main purposes: creating new knowledge and making claims to knowledge, testing the validity of knowledge claims, and generating new theory (McNiff \& Whitehead, 2010).

This research involves a study of my own practice, with a view to improving what I do. I have therefore chosen to employ an action research approach. However, there is a vital difference between practice and research. Practice aims at achieving health and improved behavioural outcomes; while research aims to improve knowledge as well asthe researcher's own practice (McNiff \& Whitehead, 2010).

Action research can be understood as having two parts, action and research. The researcher engages in purposeful practice with a view to improving practice, but is also engaged in generating knowledge about action, i.e. "what we do" and "how we know" (Mcniff \& Whitehead, 2010). Action research was defined by Kemmis and McTaggart (1998, pp. 317) as "trying out ideas in practice as a means of improvement and as a means of increasing knowledge" about a topic (Phillips, 2008). Action research is a process of improving the researcher's own learning, and promoting the growth of the researchers' clinical practice. The improvement can be made through asking questions like: I wonder what would happen if I do that; is it possible to do that; how about trying that (Mcniff \& Whitehead, 2010). Action research involves learning cycles of: planning, action, observation, and reflection. This cycle is repeated until the objectives are reached. This process is considered as a spiral or "bottom-up" approach (Phillips, 2008). Action researchers question the reasons and motivations for their actions, with in-depth questioning and meta-reflection (Brusia, 1995)

In action research the researcher's own values guide their reading of literature and other choices they might make. Unlike traditional research where the researcher holds a neutral value, in action research the researcher acknowledges that the values they hold have an impact on the research. Action research involves an examination and critique 
of thinking, to improve practice.

The researcher asks why things occurred, what can I do to change it and what can I do to change my thinking (Mcniff \& Whitehead, 2010). Action research therefore improves thinking, and the practice is better informed (Mcniff \& Whitehead, 2010). Action researchers improve their own thinking to improve their actions; and their thinking and actions have further impact on others. Participants might also change their thinking and acting as they engage with the researcher. Action research can contribute to social and cultural regeneration (Mcniff \& Whitehead, 2010).

Action research has low level of controls in the research design; it only involves one group of participants, and therefore does not necessarily represent the whole population, i.e. the results are not generalisable. However, action research reports can provide information that readers might be able to relate to, and which might be able to inform their practice. Data are collected mostly in qualitative form; however, quantitative data can also be collected. The data can be only compared within the group itself. It is considered as a weak form of research; however, it can capture more descriptive information within context. And with careful description of the setting and participants in the research, other researchers or music therapists can consider the findings in relation to other contexts (Phillips, 2008).

\subsection{ACTION RESEARCH-DESIGN AND METHODS}

I used Action Research as my research approach. In accordance with the action research approach, each cycle of learning involved planning; undertaking sessions, observation and reflection, and then further planning. The residents in the rehabilitation centre have the choice to change the activity groups they commit to, every five weeks. Originally, I intended to align my action research cycles with these activity cycles. However, my research became primarily focused on learning, for residents and myself, through the preparation for and performance in the concerts. Six cycles of learning eventually emerged.

I engaged in an iterative process of learning to improve my thinking, and in turn my community music therapy practice. I asked participants to give me feedback on my 
practice to further improving my learning, thinking and in turn my practice. My interactions had an influence on the residents, and it was anticipated that they also might change their way of thinking and their way of acting. I started with the residents and staff member's views of appropriate behaviour in the general milieu, and then acted according to their thinking to improve the general milieu (McNiff \& Whitehead, 2010). In turn, the residents' and staff members' feedback changed my way of thinking and acting (Rickson, 2010b). The primary focus of the research question was adjusted after each action cycle.

\subsubsection{Ethical Issues}

This research has the approval of the Massey University Human Ethics Committee (HEC: Southern A Application 10/53) on Tuesday $15^{\text {th }}$ of June, 2010. During the research, I referred to Massey University's Code of Ethical Conduct for Research Involving Human Subjects (Massey University, 2010).

\section{Anonymity and Confidentiality}

I used pseudonyms for the research participants including the names of the residents, staff members, family members, music therapy students and the names of the centres.

\section{Voluntary Participation}

The CEO of the centre permitted the rehabilitation centre to be a research centre, and everyone in the centre therefore became secondary participants. Because this study focused on the general milieu of the centre, I engaged in a rigorous process of on-going and collaborative negotiation about the data with the secondary participants. For example, I reminded the residents that I was doing a research project, and I obtained informed consent from the residents if I wanted to include an observation or reflection that was highly relevant to this research and affected anyone other than direct participants.

I obtained informed consent from the five interview participants, including staff and resident interviewees. Copies of Information Sheets have been included in appendices 
2 and 5, and Consent Forms have been included in appendices 3 and 6. A copy of the Authority For The Release of Transcripts is included in appendix 7.

\subsubsection{Recruitment}

All residents who were participating in a large singing group, small singing groups, concert, and other activity groups such as girls group, as well as staff members, were secondary participants. I negotiated with the potential participants whether they wanted to give me informed consent and share information that is highly relevant to the research.

\section{Resident Interviewee:}

One staff member helped me to recruit the resident interview participants. Her task involved handing out the information sheets and consent forms and explaining the research to the residents if clarification was needed. However, some of the residents only received the papers and had no understanding of the research at all. Following the research ethics guidelines, I did not want to involve myself in the recruitment process, but because of the situation, I had to explain to the residents what the research was about. I asked the residents if they want to voluntarily participate, but if they chose not to their therapy and other music opportunities would not be affected. I explained the research to participants in language that they would understand. After the explanation, the first three residents who gave me consent to be interviewed were selected as the resident interviewees.

\section{Staff Interviewees:}

I left staff information sheets in the staff room. The first two staff members who volunteered were selected as my interviewees.

\subsubsection{Data Gathering}

Data was gathered in three ways: observation, self-reflexive journal, and interviews. I made daily entries of clinical notes and important observations, then questioned my 
observations in relation to my values and beliefs in my reflective journal.

\section{Observations:}

I observed the way the residents interacted with each other. I focused on whether they demonstrated interest in listening to music or making music with each other. I observed whether they were able to support each other in their musical endeavours, and focused especially on their group process as they prepared for an end of year concert.

\section{Reflective Journal:}

I reflected on my observations, interactions, and the ways I thought about the music therapy practice. For example I asked questions like "what is going on here", "why did I do that?", "why do I think that?" I laid out my personal value and assumptions and consistently considered how they impacted on the meaning I made from what I observed. I continued to read literature and asked questions about my work in relation to what I was reading.

\section{Interviews:}

Interviews were conducted twice: before and after the six action research cycles. The interviews were semi-structured to allow staff and residents to talk about things that were important to them. Interview questions were used only as prompts to keep the interview on track. For example,

I asked staff participants and resident participants questions involving: music activities; concert preparation process; resident interaction in the centre, and general milieu of the centre. Please refer to appendices 4 and 7 for details of the interview guidelines.

\subsubsection{Data Analysis}

Interview transcripts, observations and reflections were analysed through thematic analysis, and in particular, through an inductive approach to the thematic analysis. The 
inductive approach is strongly based on the original data, requiring the researcher to have an open mind to look at the data, search for commonality and exceptions in the data, and generate tentative hypotheses. The process is "the constant comparative method of analysis", which requires processes of making of comparisons and asking of questions (Strauss \& Corbin, 1990). Each stage of analysis is systematic; however, the analysis highly depends on how the researcher makes meaning, connection and interpretations of the original data (Warner, 2011).

The analysis involves three stages: forming codes, organising codes and comparing codes to form themes and categories (Rickson, 2010a). The detail of analysis is expanded below.

\section{Forming Codes}

Raw data is labeled with "concepts" or codes. The concepts merely repeat briefly the gist of the phrase or sentence, but still describe it in a way (Strauss \& Corbin, 1990). The concept can be "meaning, practice, encounters, narrative structures, organisations or lifestyles" (Rice \& Ezzy, 1999 as cited in Rickson, 2010a)

\section{Organising Codes}

\section{Open Coding}

During open coding, the data was broken down into discrete parts, closely examined, compared for similarities and differences, and questions were asked about the phenomena as reflected in the data. Open Coding is the part of analysis that pertains specifically to the naming and categorizing of phenomena through close examination of data (Strauss \& Corbin, 1990).

\section{Discovering Categories}

After the open coding, concepts that "seem to" pertain to the same phenomena are organized into categories. The categories are not fixed, but can be shifted through Axial Coding. 


\section{Comparing the Codes to Form Categories}

\section{Axial Coding}

Data was re-organised after Open Coding, using ways that make connections between categories. This is done by utilizing a coding paradigm model, which links subcategories to a category in a set of relationships. "The paradigm focuses on condition, context, action, interactional strategies and consequences related to the events. The paradigm looks like this: (A): Causal Conditions $\rightarrow$ (B) Event $\rightarrow$ (C) Context $\rightarrow$ (D) Intervening Conditions $\rightarrow(E)$ Action or Interaction Strategies $\rightarrow(F)$ Consequences" (Strauss \& Corbin, 1990, P.99). This model helped me to think systematically about data and to relate the data in a complex way.

\section{Naming a Category}

After the Axial Coding, categories were formed. The name of a category helped me to remember, think, and analyse the content in the category. The most logical names were chosen to help me to relate the name to the content in that category. The names came from my knowledge, including concepts that I already have, concepts borrowed from literatures, and concepts that came from the informants themselves (Strauss \& Corbin, 1990).

\section{Example of the analysis process}

Interview was analysed through Thematic Analysis. In the first interview, a staff interviewee said: "Are they making music together? Not that I see. But they sing along to the radio together, at different times, different mood, different days, but $\mathbf{I}$ don't see them playing instruments. I've heard them talking about music lessons". The codes generated were: "sing along", "radio", “together", “don't' play instrument" and "talk about music therapy sessions". The codes were compared within this interview and across other interviews. The categories that generated were "residents listen to music in the milieu" and "music encouraged interaction".

Please refer to appendices 11 and 12 for examples of data analysis. 


\subsubsection{Researcher's Personal Position}

Before studying Music Therapy course, I did a Bachelor course in Science. I was influenced by the evidence based research, therefore was very tentative on interpreting the research with my own thinking. I also had piano accordion training. When I play music, I have a high "performance standard” or 'perfectionism' for myself. The perfectionism influenced my way of action especially in the early stages of the research.

I come from a Chinese background. In Chinese culture, children have pressure from parents to achieve their best in study, preferably, better than other children. This view probably influenced me to encourage the residents to do their 'very best' in the concert.

I took two years of master of music therapy training, and was influenced by clientcentred, medical and behavior approaches to music therapy. These approaches helped me to criticize my 'perfectionism' and 'musician' role and work as a therapist. 


\section{CHAPTER FOUR: MY STARTING POINT}

\section{INTRODUCTION}

This chapter contains two parts: the categories from the first concert and the categories from the first interviews. The categories from the first concert arose from observation and self-reflexive journaling. Please refer to appendices nine and eleven for analysis of observation and reflexive journal. The categories from the first interviews arose from the interview transcripts. Please refer to appendices ten and twelve for analysis of interview transcripts. This chapter was my starting point for this research.

\subsection{CATEGORIES FROM THE FIRST CONCERT}

\subsubsection{Introduction}

Shortly before this project began, residents were involved in preparing for and performing in a concert. The concert was held in conjunction with an Early Childhood Centre (ECC) because we, the staff from both centres, agreed that the collaboration would be valuable for the residents of the rehabilitation centre, as well as for the children. The following description of the events that occurred around preparing for and performing in the concert provided a starting point for my research.

\subsubsection{Categories from the First Concert}

Categories from the first concert included:

-Interaction

-Sense of Togetherness

-Collaboration between two Centres

-Performance

-Choice of Songs

-Setting and Video Recording

-My Role 


\subsubsection{Expansion on Categories from the First Concert}

The residents usually stay in the centre, and are taken care of by the caregivers. The residents were probably aware of their disability all the time. In contrast, the concerts gathered people who love music and created a "music community" or "concert group", in which the people were not differentiated by their disability.

\section{Interaction}

\section{Interaction of Residents and Staff members: Empowerment and Community}

The staff members usually supported the residents and meet their needs. However, in the concert their role switched. The residents, who are usually dependant, became the musicians. The staff members, who are usually the care-givers, became the audience. The residents' performance impressed the staff members. In particular, one staff member's eyes sparkled when he saw a deaf-and-blind resident playing the keyboard. The staff members might see the residents from another perspective. The residents were able to perform to the people, who usually gave them care. This shift of role seemed to empower the residents.

The dress code changed for the concert. The staff members usually dress in uniform, however some of the staff members came with casual clothes and one even wore fancy clothes. The casual clothes indicated that the staff members were not on duty, and they came to have some fun with the residents. The staff members also brought their family members. All these factors made the concert a social event.

\section{Interaction with Family Members: Community}

Some of the residents and staff members invited their family members. For example resident Peter's sister, and staff member Ella's grandson, came. Ella's grandson was about three. He played the bamboo chimes, bounced up and down, and seemed very happy during the concert. When the concert finished, he was still excited, and played the bamboo chimes, and banged on a small red drum. Peter's sister Eden told us she wanted to organise a ukulele band and share the music with the residents. The interaction of the family member changed the milieu; the concert became a community event rather than a performance task. 


\section{Sense of Togetherness}

By going through the practice and performance together, the resident performers probably developed a sense of togetherness or group identity. Prior to the concert, the residents practiced as a group together. In the concert, the residents sat together, and performed together as a group. The residents seemed to have developed a sense of togetherness by going through these processes together. This interpretation was confirmed by an observation after the concert: all the resident performers sat at one single dining table, chatting happily and waiting for lunch together.

It was not common that the residents sat on one single table for lunch. Usually they spread out on different dining tables, and resident Daisy usually ate in her own flat.

\section{Collaboration between Two Centres:}

The first concert was the idea of two student music therapists who worked in these two centres. After the first concert, the Early Childhood Centre (ECC) showed interest in organising another concert in ECC, and contacted our centre to organise the date. I was delighted to be involved in the facilitation of the interaction between two centres, as I presumed our friendship and communication might help the residents to have more interaction with the community and step out from their limited space.

\section{Performance or Sharing:}

\section{Performance: music skill was the focus}

Two residents played solos on the keyboard, separately. Justin is deaf-and-blind and played two songs on the keyboard. Peter played one song on the keyboard.

When Justine played the keyboard, the audience was impressed and started to sing along to the music. One staff member was so impressed that his eyes sparkled. However, when Justine made several mistakes on the keyboard, I was worried. Because he couldn't hear, he didn't know that he was on the "wrong” key. He finished his solo performance on the wrong key. The audience seemed confused because they probably had no idea what Justine was playing. So I moved Justine's hand to the "correct" key. The audience then knew that Justine finished the performance and clapped their hands. 
Peter played the keyboard after Justine. He played fluently and the audience sang along to his performance. However, Peter and Justine both chose a same song to play. Peter might be disadvantaged to have his performance after Justine's, because the audience might be less impressed after seeing Justine's performance. That I understood music as 'not perfect' or 'less impressive' was probably due to the perfectionism I tend towards. My view prevents me from seeing the therapeutic opportunity of the performance while I was instead focusing on the aesthetics of the music or music skills. However, the residents or staff members might have thought the performance was enjoyable and good enough. I will discuss about my personal stance later in the Discussion section.

\section{Sharing: Enjoyment was the Focus}

The ECC team's performance wasn't perfect, yet the audience enjoyed their singing and appreciated them to share it. Therefore, performances that are not perfect can be accepted by the audience, and the courage to step up on stage, and perform to the crowd is enough to be admired. The concert should be about sharing and interacting and residents should not be judged solely on their musical skills.

\section{Name Being Sung:}

One resident, Simon, sung a song he wrote, in the concert. In the song, he asked other residents if they've seen resident Iris. The other residents didn't mind their names being sung, but Iris felt awkward. Before the concert, Simon kept his song as a 'surprise' and didn't ask for Iris' permission to sing her name in a public situation. When Iris' name was sung in the 'public concert', she felt awkward and upset. Resident Simon had brain injury and he might not have been able to consider Iris' feeling before he used her name. Therefore, as a music therapy student, I should take extra care to protect clients from feeling vulnerable in the public situation.

\section{Well-known Songs}

Three songs in the concert were familiar to the audience. When the audience heard the residents singing these songs, they sang along without being invited. Sing-along was probably the natural response of audience on hearing familiar songs. Using well-known songs in the concert can encourage the musical interaction between performers and the audience. The residents, staff members, and teachers from ECC didn't know each other, 
yet they were able to sing together. When the audience joined in, the performers probably felt supported and felt more confident about their performance, which could make the environment warmer and more welcoming.

\section{Setting and Video Recording}

\section{Arrangement of Seating:}

The first concert occurred in the rehabilitation centre, in the big lounge area beside the dining area. The staff members organised the seating into a rectangular shape. The residents and staff members were separated by the "stage" area, and the ECC teachers and children sat between residents and staff members. This seating arrangement probably encouraged conversations and interaction within each group, but not among different groups. The residents' togetherness might be strengthened through performing as a group, as might the staff member group and the ECC group.

\section{Camera and Video Cameras:}

Both centres encouraged using camera and video cameras to keep a record of the concert. I didn't observe any discomfort or excitement due to the use of cameras.

\section{My Role:}

When resident performer Justine made a mistake at the keyboard, I was worried. I thought he should play on the "correct" key. I even corrected Justine's mistake at the end of his performance. Justine probably didn't know that he made a mistake, until I moved his hand back to the "correct" key. My action might have embarrassed Justine and emphasized the "wrong" note. However, the concert was not about playing the keyboard right or wrong, but to help the residents to express themselves, enjoy the moment, being with the community, and sharing their journey with the community. If the residents are judged on their music skills and the skills turned out to be not so good, they might feel bad about themselves, and feel disempowered.

In previous music therapy sessions, Justine said I was a good music teacher, and asked me if he played the keyboard correctly. I gave him feedback on whether he was correct or not. Justine's expectation of a music teacher probably shaped my role into a music 
teacher. I realised I focused on whether he was correct rather than if he enjoyed it. Justine chose well-known songs to play, because the songs were those he wanted to sing to his family, even though they were not in the concert. The songs have meaning for Justine, and whether he played it right or wrong shouldn't matter. Plus, it was a public situation, when I "corrected" him; he knew that he played something "wrong" in front of the whole audience, which might embarrassed and disempowered him.

When I organised the concert, I worried if the concert was going to be successful. I wanted the concert to be good, and wanted the residents to be regarded for their "good" music. I also wanted to be regarded as a good therapist who helped the residents to achieve a lot. My thinking therefore lead to my behavior: that I monitored the concert and made sure things went smoothly, and I helped Justine to play the keyboard in the “correct" way. I probably felt more secure to follow the concert program, so I didn't think or encourage the interaction through the concert.

\subsection{SUMMARY OF THE FIRST CONCERT}

The first concert strengthened the sense of togetherness, encouraged interaction, and collaboration among the concert participants. However, there were contexts and conditions of the concert that lead to these improvements. For example, the staff members organised the seating and arranged the residents to sit together. The sense of togetherness might be developed when the residents sat together. The concert venue was next to the dining area, which probably explained why the residents were sitting together for lunch.

My approach on Community music therapy was probably more towards 'Community music' than to 'music therapy'. I focused on the product, aesthetic value and 'perfection' of the concert. I should focus on the process, the sharing of the experience, and helping the residents to feel empowered. The first concert probably disadvantaged some of the residents. One resident performer was probably disempowered when I corrected his mistake. Another resident in the audience was embarrassed because a resident performer exposed her name in public without her permission.

The first concert lead to my reflection on my role in the centre, and what I needed to prepare before the second concert happened. 


\subsection{CATEGORIES FROM THE FIRST INTERVIEW}

\subsubsection{Introduction}

In the first interview, I asked the interviewees questions such as how they interacted in the milieu, and what changes did they observe since I had been at the centre. Please refer to appendix 4 and 7 for details of interview guidelines. There were five interviewees: three resident interviewees Peter, Jacob and Iris: and two staff interviewees: Susan and Abby. They all participated in the first concert. In addition Peter and Jacob joined the music therapy sessions. The findings from the first interviews helped me to understand the residents' interaction, and informed the first cycle of learning.

\subsubsection{Categories from the First Interviews}

Several categories emerged from the first interview:

-The general milieu is good.

-The residents, however, had some difficulties in the milieu.

-The staff members supported the milieu.

-Music Therapy also supported the milieu.

-Music Therapy has other benefits.

\subsubsection{Expansion on the Categories for the First Interviews}

\section{The General Milieu is Good}

In the first interviewees, I defined the word 'milieu' as 'human environment' for the interviewees.

The interviewees said that the general milieu is good in the rehabilitation centre. The residents have lived in the centre for several years, and the centre has become their home. Some of the residents share leisure activities in the centre.

Residents engage in music related activities in the centre, such as listening to music in 
their own flats, listening to the radio together during meal time; joining 'Travel the world group' or 'Karaoke night'. The residents participate in social activities in the centre, such as playing games like Wii or Buzz.

\section{The Residents, However, Had Some Difficulties Interacting in the Milieu}

\section{Not Everyone Gets Along}

The residents live in the centre, but not everyone gets along. Residents enjoy spending time with a group of residents, but they don't always interact well with some of the other residents. A small group of residents chose to 'stay in their own little world' and not to interact with other residents.

\section{Residents Have Conflicts}

Sometimes residents have conflicts or outbursts which upset all the residents. The conflicts usually happened with the residents who have had head injuries, which caused their low tolerance of noise, lack of consideration for others, and easy agitation. All the residents chose to walk away from the conflict situation, some chose to walk out of the room and some chose to "watch out for" the ones who caused the conflicts.

\section{Residents Have Routines}

Both staff interviewees identified that residents have routines for their lives. The routine can be time, places, seats, TV programs and things to do. They also socialize in the main block where the food is served. The staff interviewees said the residents had difficulties adapting to change, so staff members helped them with necessary changes.

\section{Residents are not Motivated}

Both staff interviewees identified that the residents don't initiate activities and generally display low levels of activity. Susan said:" I think they can be quite unmotivated, unless something is introduced to them, they won't self-initiate and do it themselves" and “they will just say: you organise it. When you organised it, they just wouldn't do it... and limited concentration, yeah and I don't know why they are all like that". 


\section{The Staff Members Supported the Residents}

The staff helped the residents to live and interact in the home environment. For example, staff members helped them with food and other daily needs; they also organised trips for the residents. When the residents had conflicts, the staff members solved the conflicts for them. Staff members also helped the residents to cope with change.

\section{Music Therapy Supports Residents to Interact}

\section{Music Therapy Promoted Positive Interaction among the Residents}

Music Therapy sessions and the first concert occurred before the research. The interviewees suggested that music therapy sessions promoted positive conversations. The residents told staff members and other residents what happened in the sessions, and they even invited each other to join the sessions. In the first concert, the teacher and children from the Early Education Centre participated. Both the staff and resident interviewees said they enjoyed interacting with ECC.

\section{Music Therapy Helps Residents to Work Together}

Music Therapy promoted collaborative working in the residents through setting goals and committing to responsibilities. Music therapy sessions motivated residents and gave them the responsibility to attend. Resident interviewee Peter said that "music gives everybody something to look forward to", and the staff interviewee Abby said that "music is a time and place... it's a job". Resident interviewee Iris was impressed when she saw the residents working together in the concert: "it was just amazing to see how Xinxin brought it all together, and was able to work through her groups of different people".

\section{Music Therapy Promotes Changes in the Environment}

Music Therapy lifted the atmosphere, and brought changes to the residents' routines. Music Therapy sessions were over-heard by staff and resident interviewees who walked past the therapy room, so enjoyment of music was likely to be shared. Both staff interviewees observed that in the first concert the residents enjoyed the concert and had 
their own input. Susan said that the residents were "a lot more animated than what they usually are" and they were "very enthusiastic... and it was quite nice to see all the hard work they put into practice", and Abby said "it's nice to see the consumers (residents) working on something and put it together, and then show it". Susan identified that through the music performance, the residents had some changes to their routines. The change also includes culture, as resident Peter said 'Travel the world group', and my personal background, as a Chinese music therapy student, brought new cultures to him.

\section{Music Therapy Has Other Benefits}

Music Therapy not only supported the milieu, but also aided the residents to learn new skills. The residents learned to play instruments such as keyboard or guitar in the Music Therapy sessions. However, some of the residents viewed me as a music teacher. They cared about whether the music was 'right' or 'wrong' and 'good' or 'bad. One resident interviewee practiced keyboard skill in his own time, but he compared his performance with other residents, and he attributed his own effort and success to me rather than to himself.

\subsection{SUMMARY OF THE FIRST INTERVIEW}

The general milieu in the rehabilitation centre is good, but residents have some difficulties interacting with each other. Music therapy already seemed beneficial in promoting positive interaction among residents and lifting the atmosphere. There were also some other music related activities that happened when I was not around. Therefore in the cycles of learning, I will be interested in joining or assisting these music related activities outside the music therapy sessions.

However, the residents have arguments, and some of the residents chose to isolate themselves. The interviewees didn't explain the reason and the intervening strategies that were relevant to the isolation and routines; therefore I will find it out in the following cycles of learning. In the action cycles, I will continue to help the residents to work together in music therapy sessions and prepare for the coming concert. 
The staff interviewees seemed to suggest that if residents don't do the job, the staff members will still do it for them. It seems that the residents learned no consequences for their own behaviour. Furthermore, the residents were probably dependent on staff members' support and experienced learned helplessness.

\subsection{SUMMARY OF THE STARTING POINT SECTION}

The findings of the first concert and first interview were the starting point that informed the Action Research cycles. Music encouraged conversation, and seemed to improve the atmosphere in the centre, so it felt important to look more closely at the possibilities for this to increase. A further concert was therefore planned as a result of the success of the first. I was interested in finding out what causes residents' difficulties in interaction, isolation, and/or routine, and what I could do to help them. 


\section{CHAPTER FIVE: FINDING FROM ACTION RESEARCH CYCLES}

\section{INTRODUCTION}

This section contains six cycles of learning. Each cycle contains four sections; 'planning'; 'action'; 'reflection'; and 'things to improve'.

This chapter includes the following sections:

-Cycle 1: Preparation for ECC concert;

-Cycle 2: Practice for ECC concert;

-Cycle 3: ECC concert (the second concert);

-Cycle 4: Resident prepare for the Pre-Christmas concert, and re-grouping;

-Cycle 5: open group;

-Cycle 6: Pre-Christmas concert (the third concert).

-Summary

\subsection{CYCLE 1: PREPARTION FOR ECC CONCERT}

\subsubsection{Planning}

Based on the information I had obtained, and which was described in Chapter 4, I decided to help participants to prepare for another concert. The date of the ECC concert was set and we needed to decide what songs to sing. We only had one month to prepare for the concert. The most important aspect of this cycle was to consider how residents can work together as they practice for the concert. I thought the residents would have difficulties preparing new material in this tight time frame.

Although I had thought it would be important to encourage more residents to attend concerts to support their fellow residents, the concert venue in ECC was unfortunately 
small and prevented large number of attendants (see below). It seemed logical that those who practiced in the singing group would go. Other residents would be offered a seat when there was space left for the concert.

\subsubsection{Action}

Preparation for the Concert: Idea Gathering and Decision Making.

Residents who attended the first concert showed interest in coming again and they talked to each other about it. Lily and Jacob both told me that they wanted to be part of the concert and would put some effort into it, and they would look for some songs. Lily suggested we sing 'Eternal flame' by the Bangles. This song was hard for the residents to sing. Jacob said he would bring his CD but he didn't. Jacob suggested a song 'Turn on the Sun' which was easy for the residents to prepare. Other residents agreed to think about what songs to sing but didn't come up with any ideas. I had to ask them if the songs I suggested were ok and the residents came up with yes or no answers. One staff member Olivia suggested the residents were not able to manage complete freedom of choice. She identified that the residents each came up with different ideas, and when they couldn't make a decision they became anxious. Olivia concluded that it would be best to offer the residents just two or three ideas. Because of the limited time frame and residents' musical ability, I proposed two familiar songs, including 'Turn on the sun' suggested by Jacob. The ideas were accepted by the residents. I helped the residents to practice for these songs in smaller group or singing group sessions.

\section{Preparation for the Concert: Gear up the Musical Skills.}

In smaller group or individual sessions, the residents practiced their music skills in preparation for the concert. In Peter and Simon's smaller sessions, I found they could play together. Peter could play chords on the organ or keyboard, and Simon could play $\mathrm{D}$ and A chords on guitar. When we practiced the chords together, it sounded really good.

During Tom's individual session, he practiced the song 'Hot Cross Buns'. He had just started to learn the keyboard, he could find the key to start the song and could play a glissando to end the song, but sometimes his beat was not very consistent. Tom was 
confident performing this song to the children in ECC.

Preparation for the Concert: Responsibility and Motivation.

The residents who would play an instrument for the concert were motivated to practice; however the other residents who were not assigned to tasks seemed unmotivated. Tom and Peter who played solo on keyboard practiced hardest of all. However, the others were not so keen to practice and were just coming to the group session and "enjoying" the singing. The work involved constant repetition, we practiced for about two to three weeks on the same two songs, and I began to suspect the residents were bored.

\section{Working Together in Music: Listening to Each Other.}

I used interactive songs to help the residents to listen to each other's singing, to help them to transfer the skills into daily lives and listen to each other's talking.

There was a hello song that went really well in this group, in which the group sang hello to each member of the group. While singing this song, the residents need to pay attention to the name he other residents were singing, and respond to each other. The group enjoyed this song, enjoyed the cheekiness, and paid attention to residents' names. Sometimes, one resident was confused about whose name was sung, and other group members reminded him. It showed most of the residents listened and responded to people around them. One resident even put humor in the song by slightly modifying the lyrics.

\section{Working Together in Music: Leading and Following.}

I invited the residents to be the conductor, and the rest be the band. The residents who were the conductor gave clear instructions to the band, and the residents who were the band looked at the leader and followed the instruction. They seemed to enjoy this musical activity.

In one of our group sessions we rehearsed the song 'Turn On the Sun'. I asked the residents to volunteer to be a conductor. Julie was the first volunteer conductor. She turned both palms up to indicate "are you ready", and waved her hand in the beat of the song to indicate "start and follow my beat". She was also aware of loudness and when 
we came to the chorus part, she said "shh". Julie seemed to be good at it. The second conductor, Lily, said her father used to be in a choir, and she showed us her way of conducting. The residents took turns to be the leader enjoyed it. Other residents, who were always the followers, followed the leader's instruction and also enjoyed it. I realised I introduced this activity as a "conductor game", however I could really encourage the residents to conduct during the practices, and in the actual concert.

\subsubsection{Reflection}

My Reflection: Why Did I Use Interactive Songs to Help the Residents Listen to Each Other?

I used call-and-response songs to help the residents to listen to each other, in the hope that they could generalise this skill into their daily lives. I realise that verbal instruction of "you should talk after another person has finished" didn't work, probably because 'talking at the same time' was an established behavior among the residents. Previously, I worked with children who couldn't comprehend the verbal instructions, so I used songs and music to help them listen to each other. Music reinforces the good behavior of listening to each other.

\section{My Reflection: Why Did I Select “Easy” Songs?}

I realised that when the residents suggested songs to sing, I decided if the songs were easy or hard, and encouraged them to sing the "easy" songs. The performance aims to improve the residents' confidence and to empower them; therefore the songs shouldn't be too difficult. However, I judged if the songs were easy or difficult based on my music knowledge and even on my confidence to perform the songs. I didn't know if the residents wanted to sing the songs that seem "difficult" to me, but are familiar to them.

\section{My Reflection: Why Did the Residents Need to Improve on Their Music Skills?}

I assisted the residents to practice for the ECC concert. I wondered why I assisted them to practice. I had personal experience of performing in concerts, and I thought before the concert, the musicians would need to practice again and again. However, the residents probably thought they were good enough. When I asked them to practice again 
and again, they might think that they were not good enough.

\section{My Reflection: My Role as a Therapist}

As a therapist, I didn't stress the group responsibility that the residents should play their part in supporting each other in the concert. As a group leader, I thought I should be responsible for organising the concert; therefore the residents didn't need to do anything. As staff members identified, the residents lack motivation and tend not to give input. My leadership style probably reinforced the residents' lack of commitment. Rickson ( 2009) stated that music therapy students might have difficulties in defining the boundaries of their music therapy work. In the future, I should assign the residents to tasks they are responsible for, such as asking them to play in the "band".

\section{Lack Of Motivation: Residents Didn't Make the Decisions, And My Leader Role Was}

\section{Too Strong.}

I gave the residents a limited choice of songs to sing. Because of the limited preparation time, I suggested songs that were familiar to them and easy to sing. This plan seemed “safe", but probably led to the residents' lack of motivation. However, if I allowed ideas to rise throughout the practice, residents would probably come up with a song thatwas hard for them, but they were willing to practice for. As a group leader, I didn't really offer the opportunity for decision making; instead I let them choose "yes" or "no" from what was available instead of offering them "whatever you want to sing will be ok". Also, my previous music training made me feel the songs needed to be really "prepared" before they can be "performed" in the concert, therefore I put a high standard on the residents and organised them to practice again and again.

\section{Lack of Motivation: Resident Responsible for Solo were Motivated}

The residents seemed to think the concert practice and rehearsal was a come and go thing, and their participation would make no difference to the outcome. It seemed as if it would be helpful to give them a task to do, and to encourage commitment, stressing that their contribution was important to group outcomes. I think the concert helped them to learn there was something they could change, and they are able to make a difference. 
I also realised their lack of motivation might be due to a lack of a clear role in the concert. The ones who are soloing or those who needed to play an instrument were keener and more committed to practice and came to the group sessions. Tom was practicing his keyboard skills inside and outside the sessions, and made great improvement on the skills, even memorising the fingering. Others were less keen, and some were late for practice, possibly because they didn't feel such a strong sense of responsibility. The residents who were singing with the group might have seen their roles as less important. This might be partly due to the shared role of the group, but also might be due to their learned helplessness, i.e. perhaps they though the concert would be fine whether they worked hard or not. Some of them didn't have a sense of working together as a group. Julie, for example, wanted to come to, and perform in, the concert but would not attend practices. Some of the other residents, for example, Peter, the keyboard player, and Simon, the guitar player, were happy to solo but a little anxious about working together in teams.

\subsubsection{Things to Improve}

\section{Should Stress Residents' Responsibility in a Group}

I should change my way of thinking and acting. I thought I should be responsible for the concert, therefore the residents thought they had no obligation for the concert. I will ask the residents to give input for the concert, and stress the responsibility they have. For example, I might invite them to play an instrument in the "band" and tell them it's important to have them in the band.

\section{Keep Going with the Music Therapy Strategies that Encourage Resident to Listen to Each Other in Music}

In contrast, activities within the sessions aimed at helping residents to know when they should listen to each other, and listen to the person who was talking: the "leader" or the “conductor". I think through the music interaction, they seemed to enjoy the songs, and respond to each other well. 


\subsection{CYCLE 2: PRACTICE FOR ECC CONCERT (SECOND CONCERT)}

\subsubsection{Planning}

For this cycle of learning I will continue working with residents while preparing for the ECC concert. We would practice singing and playing instruments. The keyboard soloist, Tom, joined the practice session. Staff members told me two residents had had a conflict recently, and they were in one small group together, so I was challenged to support their interaction. I would use structured songs or music activities to help them work together in music therapy group session. This cycle of learning is short, because I focused on one practice session. The concert is described in detail in the next cycle of learning.

\subsubsection{Action}

\section{Preparing for the Concert: Low Session Attendance}

In a practice session preceding the ECC concert, only two residents came; and the others made unconvincing excuses for not showing up. There was a noticeable group dynamic that when resident didn't show up, the others left too.

Residents who were supposed to practice for the ECC concert usually attended sessions regularly. However, they didn't show up to the practice session preceding the concert and came up with lame excuses. Catherine, Lily, and Simon, were in the rehabilitation centre. Catherine said she didn't need to practice because she had plans on the day of the concert. Lily said she had "something else to do"; and Simon was in the shower. Jacob was not back from voluntary work. Tom was five minutes late for the practice session, but he was still the first one to arrive. When he saw no one else in the group session room, he left briefly and did some of his own things before returning to the session. Lucy arrived later and said she would be away for several minutes and back as soon as possible, but she didn't come back. She has short term memory loss, so she probably forgot to come back. Peter came, but he said he had something else to do, and said he preferred to come to the practice on Friday. Julie came and heard Peter's 
conversation, and immediately said she also wanted to practice on Friday so she left the room. It happened quickly, and I didn't even have time to give any response to Julie before she left the room. In the meantime I was able to encourage Peter to stay.

\section{Preparing for the Concert: Musically not Prepared}

The residents who were the keyboard soloist, Tom, and 'band' keyboardist, Peter, came to the practice session preceding the concert. However, the 'band' keyboardist Peter was not prepared to play the keyboard.

Peter said he hadn't learned the chords yet. The song he played was 'Turn on the sun', which he was very familiar with. Peter started to play the keyboard with my encouragement. Each line he played, he read the sheet music, searched for keys and then played the song. It took a long time, and Tom seemed to become impatient. Tom had individual sessions and was prepared to play the keyboard solo. I thought it might waste Tom's time watching Peter 'learning' the song on the keyboard. I then cancelled the practice group.

\subsubsection{Reflection}

\section{My Reflection: Why Did We Practice for the Concert Again?}

During Cycle One, the residents already showed signs of lack of motivation relating to the repetitive practice for the first concert. In Cycle Two, I continued to organise the residents to practice for the concert. I realised that I still felt uncertain if I don't practice with the residents before the ECC (second) concert.

\section{My Reflection: Why Did I cancel The Session}

I wondered why I cancelled the session instead of inviting the two keyboard players to practice during this time. I hadn't checked with Tom about how it was for him when he was waiting for Peter, but presumed he was bored. Perhaps I also thought Tom had done his practice and all he needed to do is come to the group, and play in front of others to get a sense of being "on stage". I thought Peter needed to have more practice, and if 
Tom stayed and watched Peter playing, it might be a waste of time for him. They were going to use the same keyboard to play two different songs, so there was no way they could share the keyboard and play together. I also recalled impatience from Tom when he was waiting for the group to come.

Peter said in a joking way that he hadn't done enough practice and I might give him a smack. It was usual for him to say that he hadn't done enough practice. It seems that he has high standards on himself and sometimes even compares his music skills with the other residents.

I recall I was angry because of the low attendance and unconvincing excuses. I felt that they needed to learn the consequences to their behaviours: that if they don't come or don't come on time, music therapy session would be cancelled. However, most of the residents weren't there to learn this lesson. On Friday, we practiced together, this time everyone attended and we practiced together. Itwas possible that Peter and Tom told them there was no group on that day, or maybe they knew the concert would happen in the next week, so they had better practice.

\section{Group Dynamics}

I felt that Julie, Tom, and Lucy were influenced by the lack of attendance in the practice session preceding the ECC concert. Julie was especially influenced by Peter because he said he wanted to come back another day. When there were only two residents in the group session, they might think we are not having a serious session. When one out of the two residents was trying to leave the room that probably strengthened the other's idea that this session was not important. Julie was influenced by Peter, thus he was not a good role model.

\section{Commitment}

Julie normally doesn't come to the group session. She told Lily that she wanted to come to the ECC concert, but not the practice. When she saw others weren't coming to the practice, it gave her a reason to stay away. I reflected on her normal behavior, that she comes to music therapy sessions whenever she likes, which probably led to her behavior 
in the concert practice session. When taking part in individual sessions, the residents are only responsible for themselves. However when taking part in group sessions or concert performances, the residents are responsible to the other residents in the group. When they don't show up, the other residents are disadvantaged from not having a vocalist or a band member. Julie wasn't assigned to any roles, so she does not seem to have the same sense of obligation to come.

I reflected on the previous encounter with Catherine. Catherine had expressed interest in being interviewed as part of this study but also seemed relieved when I told her that I already had the participants I needed. It seems that Catherine doesn't like to be bothered by responsibilities, and if there are things she doesn't need to do, she wouldn't do it.

When I talked to some of the staff members, they identified the same pattern: the residents would rather not attend activities preferring to stay in their flat doing nothing. One staff member told me, that some of the residents keep saying no, as that's their only chance to choose. They possibly felt empowered by refusing the therapist. On the other hand, the centre wanted the residents to get something out of their days, and not just stay in their own flats and sleep. Therefore staff members were trying to persuade the residents to commit to the programs. In the centre, the programs are run in five week periods. The residents can chose to come for five weeks, and then not come for five weeks. As a therapist, I should help them to commit to a certain period of the program.

\section{Should Stress the Group Responsibility}

Only the soloists demonstrated commitment and responsibility by coming to the concert practice, and I had to cancel this session. The residents were assigned specific tasks for the concert, singing or playing an instrument. Tom was to play a keyboard solo, and Peter and Simon were to play keyboard and guitar accompaniments, while other residents sang and accompanied with percussive instruments. The soloists or resident band members came to the practice sessions, while the other residents had unconvincing excuses for not showing up.

I realised that the soloist who was self-motivated showed better commitment to his responsibilities. 
Tom was self-motivated to learn the keyboard and perform in the concert, therefore he was more motivated to practice on the skills and he showed better commitment to the sessions. Peter, on the other hand, was assigned to the role of the keyboard band member by me. He agreed to play but he probably doesn't have the high motivation that Tom does. Therefore he attended the sessions but didn't practice outside the sessions.

\section{Limited Entry Concert, What's the Impact}

My clinical liaison and I agreed that residents who were not performing in the concert would not be able to attend, because space was limited at the venue. Therefore, I told the residents in the group sessions that if they came to the practice, they could be guaranteed a seat in the ECC concert. I didn't say they needed to come to all of the practice sessions.

The limited space also meant that there would be less staff members and residents in the audience, and the resident performers had less chance to show their abilities in front of other people they see regularly.

Also, we had just three weeks to rehearse for this concert. Our residents only needed to perform two or three items, because concert time was also limited, and we choose items that would be suitable for the children at the ECC. Perhaps our residents were not interested in the songs, and/or their tasks were too easy. So they might have been less motivated because they were not singing songs that they love. Although I consulted them about the repertoire, I suggested songs that we knew, and that I thought were achievable.

\subsubsection{Things to Improve}

I wanted the residents to have their input for the concert, either through their choice of songs or musical activities so they might be empowered to become more autonomous. I wanted them to think they were singing "their" songs in "their" concert Also, if I encouraged them to take a "very important" role such as playing one part of a song, it might help them to develop a sense that they were in control of the performance and they could influence the consequence of the song and even the concert. 


\subsection{CYCLE 3: ECC CONCERT (THE SECOND CONCERT)}

\subsubsection{Planning}

The concert happened in an Early Education Centre, therefore we had to travel to ECC. I gave the staff members a list of the resident participants, and the staff members organised the travel. Resident participants would be divided in two groups, one would travel by van, and the other would walk to ECC.

The concert venue at the ECC is small, so residents who practiced for the concert were given priority to attend, and others missed out on coming to hear it. Eight residents who attended the music therapy sessions and four other residents who didn't attend the session participated in the concert. There were a smaller number of resident participants compared to the first concert.

\subsubsection{Action}

\section{Interaction}

There was interaction during the concert. Every participant sang the Birthday song to a resident Lily with the guidance of another music therapy student Sophie and I. One resident told the Music Therapy student Sophie a joke, which was appropriate and made everybody laugh. Sophie performed a song on the behalf of an ECC child to the child's mother, who enjoyed and appreciated the song.

There were two interactive activities in the concert, one with the parachute and the other involved drumming. The participants mainly focused on the music therapy students but didn't interact with each other. The structure of the parachute song probably didn't allow room for interaction. The drumming aimed to encourage the participants to listen to neighbours and play different drum beats. However, the participants listened to the leaders and played drum beat in unison. The participants were likely to have remembered the 'drumming rules' from our first concert; it is also likely that they felt more secure to follow the leaders.

Residents expressed appreciation to the ECC. Jacob said a prayer before the morning 
tea; Iris said her appreciation to the ECC; and Julie carried plates of food around and offered them to people. Both Jacob and Iris asked for the leader's permission before they expressed their appreciation. It was the first time I had seen the residents take initiatives and proceed with tasks in a socially appropriate manner.

The interaction listed above changed the atmosphere of the concert and improved the sense of community.

\subsubsection{Reflection}

\section{Sense of Togetherness}

The residents probably didn't build up the sense of togetherness as a whole group, but perhaps the two smaller groups developed a bit of a bond as they travelled. The residents seemed to enjoy the experience of travelling together and having a concert in a different place.

When the residents came back to the centre, most of them went to their own flats, possibly because of tiredness. Two residents Iris and Lucy went to dining area. They sat at two different tables, and Iris who expressed her appreciation in the concert, complained that Lucy's wheelchair hit the dining table. This might mean that the concert improved the milieu and changed the residents' behaviour only for a brief time. However, people may act differently when they are outside and at home. It would be worth comparing the residents' behaviour during and after the concert.

\section{Residents Were Less Nervous}

It seems that Peter was slightly nervous when he was asked to play the keyboard, however he seemed relaxed when his music started. His beat was stable. Maybe he was more experienced in participating in concerts, and his role to accompany rather than solo took the pressure off him. 


\section{Things Did Not Go According to the Plan}

One song and the drumming activity turned out to be different than what we planned. However, the participants joined in and enjoyed the music. Sophie emphasised that the ECC concert was a "sharing concert", which probably helped the participants to relax about the uncertainties in the music.

\section{Benefit of the Concert}

Robert and Bob were on short care in the rehabilitation centre. They went to the concert, and seemed to enjoy it as they had big smiles while playing the percussion instruments. After the concert, Robert expressed willingness to join in the music therapy group session. In the end, both Robert and Bob joined the group music therapy sessions. It seems that the experience of the concert was enjoyable, and gave Robert and Bob an idea of what to expect from the music therapy sessions.

\subsubsection{Things to Improve}

\section{Improve Communication}

One resident, Tom, was left out. I told Tom the date and time for the concert, and expected him to come by himself, but didn't inform the staff member that Tom was coming. However, it seems that Tom waited for the staff member to tell him, but showed no initiatives with regard to check the time himself, or to gather with other residents before the concert. The residents were used to the staff members organising things for them, and they lack the skills to organise things for themselves.

\section{Improve Arrangement of Seating}

The space in ECC was small, therefore the concert participants had no free space to move and they had to sit where they were. The crowded seating probably prevented concert participants from interacting. The ECC teachers and students sat behind a big children's table during the concert, which probably acted as a physical barrier to interaction. During the morning tea time, a table was moved to the centre of the room to 
help in the serving of food, which probably also acted as a physical barrier. The seating might need to have more free space to encourage the interaction between the concert participants.

\section{Encourage Interaction in the Concert}

In the second concert at Early Childhood Centre, the residents seemed to enjoy more interaction with the audience. In the next cycle, I will find out what their feedback about the concert. Also, continuing from cycle two, to empower the residents, I would involve them in the decision making process for the group session and for the next concerts.

\subsection{CYCLE 4: PREPARING FOR THE PRE-CHRISTMAS CONCERT, AND RE-GROUPING}

\subsubsection{Planning}

I planned to involve the residents in the process of preparation for the Pre-Christmas concert. I would ask the residents to give feedback on the previous concerts, and to hear their suggestions about songs and ideas for the up-coming concert. I would ask the residents and staff members whether to have open groups.

\subsubsection{Action}

\section{Residents' Feedback on Previous Concerts}

In the music therapy group session following the ECC concert, I asked the residents what they enjoyed from the ECC concert. The residents were very excited when they talked about things they enjoyed: some enjoyed interacting with the children, some enjoyed walking to the ECC, some enjoyed playing with the parachute and the drum; and some enjoyed trying something new. They talked after another resident had finished, and commented on different aspects that they enjoyed. It indicates that they listened to what other people said, and they gave other people time to talk. 


\section{Residents' Input}

Residents' feedback provided a starting point for preparing the third, Pre-Christmas, concert. The Pre-Christmas concert would include some interactive parts, such as playing the drum together. I asked the residents what songs they want to sing and encouraged them to bring CDs to the session, so that we could choose the songs together. The residents didn't suggest songs to sing. Tom brought a Christmas Carol $\mathrm{CD}$. We listened to the $\mathrm{CD}$, and I asked the residents to choose from songs in the CD. I asked the residents to vote for the songs they want to sing, and we chose the three songs that won most of the votes. The group consensus included every member's ideas, and enabled the quieter members to have an opportunity to express their opinions.

However, Lily suggested that the songs the residents chose were probably too difficult to sing. I asked if the residents still wanted to sing these songs. One resident said, we should still sing 'I saw mommy kissing Santa Clause', because another resident Julie would love it. The other residents however agreed with Lily, and said this song would be difficult to sing. The group therefore decided to follow Lily's idea, and sing other Christmas Carols that were easier, such as "Jingle Bells". The idea of a group member was supressed because she was the minority; also the other residents didn't follow the choice they've made through consensus. However, it was good that the residents adjusted the songs to their ability.

\section{The Session Attendance was High}

The resident performer group developed from six residents to eight residents. The residents attended the sessions on time, and attended every session. Catherine, who would be away on the Pre-Christmas concert, came to the practice session. She didn't contribute to the decision making process, but she joined the singing.

\section{Music Improvisation}

In the previous concerts, the residents had no time or chance to interact with people from the ECC. Resident Iris even called them "strangers". The interaction among the concert participants was important for developing a sense of togetherness and enjoyment. Therefore, in the coming Pre-Christmas concert, the residents could 
introduce themselves to the guests. I would play four chords on the guitar, and the residents would sing or say their names and a short phrase to the guests. For example, I would sing "My name is Xinxin, I'd like to say hello". Simon and Peter knew how to improvise, so they demonstrated for the other residents. Other residents were tentative at first, but then they enjoyed it and wanted to improvise in the Pre-Christmas concert.

\section{I assigned Tasks to the Residents}

In Cycle Two the residents were still showing a lack of motivation. I interpreted that was because they didn't have responsibilities for the concert. Therefore, in this cycle while we prepared for the Pre-Christmas concert, I assigned the residents to different tasks. I gave the residents tuned bells and instructed them to play in two chords for the song of 'Jingle bells'. I emphasised who should play which bell, and expected them to come to the sessions and the concert. The residents enjoyed the sound of the bells, and some of them were able to remember their tasks.

\section{Re-Grouping}

The residents showed interest in other residents' music therapy group sessions, and joined each others' sessions. Two residents, Bob and Robert, joined a small group. The group had two regular attendants, Simon and Peter. I gave the four residents clear instructions, and asked them to sing together, or play an instrument while their name was sung. Simon and Peter were very friendly, they encouraged and demonstrated for the new-comers. Bob and Robert were able to quickly tune-in with the other members, they joined in and sang with us. Usually people would feel insecure when they were asked to improvise, and especially when they enter a new group, however, with the encouragement of Simon and Peter, Bob and Peter were able to join the musical improvisation.

Another resident, Julie, joined the session with Lily and Jacob. Julie entered the music therapy room when Lily and Jacob were listening to the song 'Memories' from the Cats Show. Julie enjoyed the music, sat close to us and sang to the music. However, Lily asked Julie to keep quiet by calling her name "Julie!" Julie kept quiet and walked to the other side of the room. She was probably still interested in the music, and joined in the 
conversation with Jacob and Lily. However, Lily asked Julie to keep quiet again. Julie was probably unhappy and left the room. I realised that I didn't say anything when it happened.

I asked senior staff members and all the residents if it is possible to have open group. They all agreed except one resident in the individual music therapy session. Therefore it was possible to have open groups.

\subsubsection{Reflection}

\section{Residents Were Involved in Planning the Concert}

The residents were involved in every step of decision making, from feedback, suggestion, to vote, and the final decisions regarding the songs in the Pre-Christmas concert. I felt released because I was no longer the only one who is responsible for the concert, but the residents and I were doing it together. The residents might have felt more responsible for "their" concert and it's no long Xinxin's concert. I realised the residents were happier and more motivated. Their high attendance, high motivation, frequent suggestions, punctuality, and commitment to regular and extra practices all suggested their commitment to "their concert".

\section{Decision Making through Consensus}

Previously in the session, decision making was either done by me, or the first few residents who suggested their ideas. In Cycle Four, we made a decision together by vote, and the majority would decide whether to sing the song. The group consensus probably involved everyone's idea, but if one individual disagreed with the majority, the individual's idea would be supressed.

\section{The Residents Were Empowered}

Involving residents in the preparation process for the Pre-Christmas concert could empower the residents. Their feelings about the songs they enjoyed were important, and their preferences could in turn lead to a consequence: the third concert. Each resident 
was responsible for playing a single bell. The responsibility was distributed to every member in the group, and the individual members might think they are equally important for playing the bells. This might also empower the residents as their attendance leads to the successful performance of the song 'Jingle Bells'.

\section{Possibility to Have 'Open Groups'}

Julie joined Lily and Jacob's session, but Lily asked Julie to keep quiet. I wondered why Lily did that. Maybe she thought it was inappropriate for Julie to sing while she was trying to listen to the music; maybe she is now an "old member" and therefore a "rulemaker" in the group, so she has the right to tell Julie to stop. I also observed that sometimes Julie's behaviour was inappropriate, and people surrounding her asked her to stop by calling her name. Lily may have observed others using this kind of behaviour. As a group leader, I kept silent when Lily asked Julie to be quite. I probably wasn't exactly sure what the group rule was: whether we should sing along to the music, or sing after we listened to the music. In music therapy sessions, I encouraged sing-along, but in other music related group 'Travel the world group', I encouraged the residents to listen to the music, and talk about the song afterwards. I didn't give any comment on Lily's behaviour, so both Julie and Lily might have thought it was acceptable for Julie's name to be called that way. However, I should have told Lily that calling Julie's name in that way was wrong. Therefore it was important for me, as a group leader, to know and apply the group rule in the appropriate situation. The small group seemed to have a problem, that the regular members established their own ways of interaction and preferred to stay in their own group. Staying in a small group for too long might have prevented group members from mixing with other residents. Therefore it was beneficial to invite other members into this group or invite this group to join other groups. As a result, the members in the small group might relate more flexibly with other clients in the centre.

In another group, the regular members, Simon and Peter, accepted and supported the new-comers. Therefore the open group can be developed with careful consideration of the possible members. Directing the music therapy activities in a quite structured way seemed to help the members to work in the open groups. It is also good for them to work together in an open group rather than in smaller groups. The open group more closely mimics the real milieu of the centre. 


\section{Re-define the Word Milieu}

When I read my observations, I realised I focused mainly on interaction. Interaction might be one important aspect of the general milieu but there should be more to it. I felt I need to re-define the word milieu.

\subsubsection{Things to Improve}

I need to plan the concert in detail. Throughout the practice for the concert, I need to keep asking suggestions from the residents and to get them involved in the process. I need to advertise the concert to staff members, residents, guests and families ahead of time, so they have time to organise and be prepared.

I need to consult staff members' ideas about the concert, including the setting and organisation.

I would like to invite some staff members to come to the music therapy sessions, such as Music with Movement sessions. This might enable them to continue with the music activities when my placement finishes (Croxson, Donald, \& Parsons, 1989).

I will work on open groups based on the existing groups. The current groups have different members, and over time we developed different themes, such as: music with movement; song listening; improvisation; singing; and concert practice groups. These groups might develop into groups with similar theme, or one-off groups like musical games groups or keyboard workshops. I might invite the residents to stay in their original groups, and come to other groups. I might invite staff members to join us, and to give us suggestions on physical rehabilitation or social interaction. I might ask the residents what kind of open group they want.

I felt I might need to re-define the word milieu and re-define the focus of observation and study. 


\subsection{CYCLE 5: OPEN GROUP}

\subsubsection{Planning}

I decided to plan the concert in detail, includes inviting family members, informing staff them about the concert participants, and consulting staff members about location of participants. I would organise the concert rehearsal with the residents. After the concert, I would consult residents about what kind of open group they would like, and use turntaking and call-and-response strategies to manage large open group music therapy sessions. I would also invite staff members to come to some of the open groups.

\subsubsection{Action}

\section{Redefine milieu:}

Milieu describes the immediate environment the people are interacting with, in comparison; environment is the general environment the people live in (Aasgard, 2010). Therefore the milieu involves sense of belonging, sense of togetherness, and sense of community.

\section{Inviting Audience for the Pre-Christmas Concert}

I invited resident Celeb to come to the concert. He said he would probably be out on that day. At lunch time, Frank and May told me they would like to join the concert. Frank said he wanted to do the Haka with Jacob since he had enjoyed this in the first concert. I was very happy that they wanted to attend.

\section{Christmas Decoration in the Centre}

In the dining area, the windows were decorated with Christmas theme stickers, the ceiling was decorated with hanging ornaments, on the table there were small statues of Mary, Joseph and baby Jesus, in corner of the room was a Christmas tree. The decoration was Christmassy; maybe the staff members decorated it early for the concert. I imagined the residents might be happy and "Christmassy" before the Christmas. 
However during lunch time, two residents had a small argument, and one staff member said maybe their behaviour wasn't so Christmassy.

\section{Rehearse for the Pre-Christmas Concert: Teaching Haka}

Six resident performers participated in the session. Jacob was very keen on doing the Haka and singing Maori songs for the Pre-Christmas concert. When Jacob did the Haka, Tom said he always wanted to learn the Haka since school age. Jacob demonstrated the Haka to Tom. Tom is vision impaired and has difficulties in picking up the movement. I asked Jacob if he could slow down or break down the actions for Tom to learn, but Jacob said he cannot slow it down because that's the way it is. However Jacob demonstrated again. This time I checked with Jacob if I could describe his actions, such as "pat on the knees" so that Tom can follow. Jacob agreed and demonstrated again. Jacob demonstrated three times in total. He demonstrated patiently, and I observed him slowing down for Tom. Tom was very happy he could learn the Haka, and Jacob seemed to express "It's just a small favour". It was not common to see Jacob offer help to other residents, especially with the great patience he demonstrated when he had to do the same thing three times. The interaction between the guys was very nice and friendly. The female residents didn't join the actions, but they were observing without talking.

\section{Rehearse for the Pre-Christmas Concert: Singing Maori Songs}

The residents practiced singing the Maori songs together. Jacob and the female residents knew the songs from school, so they sang together. Tom didn't know the song and couldn't see the small print lyrics, but he still joined us and sang with us. We discussed whether we should sing the songs once or twice, and if we should sing each verse or only the verse we were familiar with. The group voted, and we decided to sing the familiar verse with the chorus, twice. Jacob suggested we could end the song with Maori numbers of "one, two, three and four". The group agreed. The female residents started to share their story of singing the Maori songs at school, and they all had common experience of singing the same songs at school. Peter didn't join the conversation, and we realised that his head had drooped and he had fallen asleep. When Peter woke up, he explained that he just didn't understand the language. Peter joined the rest of the rehearsal. 


\section{Rehearse for the Pre-Christmas Concert: Keyboard}

Tom rehearsed his keyboard playing. When he was playing, people started to talk. After the session, Tom told me he didn't like people talking while he is playing.

\section{Possibility to Have Open Groups}

I consulted the residents about what they wanted for the open groups after the concert. They were happy to have open groups, but they didn't give me any suggestions on what they wanted. So I proposed four options: Keyboard one-off session; guitar one off session; improvisation or music making session; or musical games session. Lucy said she didn't want to learn an instrument. She didn't have time to propose what she wanted, but it seemed as though she wasn't satisfied with any of the options. She is usually a quiet member; takes a long time to think and usually doesn't come up with any ideas. I then started to ask the residents to vote for one out of four ideas, and keyboard or guitar sessions won the vote. We decided in the open group, the first half of the time would be a keyboard session, and then the second half would be a guitar session.

\section{Open Group}

The open group occurred, and eight residents showed up. The music therapy room became crowded. I wasn't expecting such high attendance, and we only had one organ and one guitar. I asked the residents what they would like for the group, Jacob said, I don't know, I'm just told to come. The residents seemed happy to be together. Tom started a conversation about cricket, all the male residents and some of the female residents started to get excited about the topic, and started to chat. In the beginning, they waited for another person to finish the conversation before start their conversation. Later on, they were all excited and trying to talk, and started to talk at the same time. Their voices became louder and they seemed trying to cover up other people's voices. I reminded the residents we should talk one at a time, and they went quieter.

Because of the unexpected high attendance, it was hard to share the instruments. I decided we could play a musical game; spin the shaker. When the shaker points at one resident, that resident play one instrument, and the rest of the residents accompany with 
clapping or drumming. Simon took the guitar and waited happily for the music game to start. Other residents took other instruments. Jacob said to Simon: "It's not your guitar". Simon seemed hurt; he stood up and left the room. I tried to encourage Simon to stay but he still left. Jacob probably realised what he did was not right, so he said: I will shut up. The rest of the session went smoothly.

The physiotherapist, John, came and observed one music and movement session. Jacob had been requesting that he come to see the session for a long time. I also invited John to come. John observed our movement briefly and suggested Catherine might sit down so she can focus on her neck movement without worrying about her balance. Iris said she always wanted to show John our music and movement session, so they could continue the session when I'm not there. I encouraged her good idea, and left a copy of the music we used, on the residents' computer.

\section{Sharing Information with Staff Members}

Staff member Kate chatted with me, and showed interest in the music and movement session. She expressed willingness to see the session when she gets the chance to. I explained to her how we could use music to encourage movement, such as using the rhythmic aspects of music to encourage movement or relaxation.

Staff member John helped me to work with residents' physical rehabilitation tasks, while avoiding falls and other risks. I planned to teach John how to use music to encourage movement, but I didn't get the chance to. However, I got the chance to explain it to Kate. I felt re-assured when I shared knowledge with other staff members. I thought the residents would also benefit from it, because the staff members would know better how to work with them, and residents could have music with movement sessions when my placement finishes.

\subsubsection{Reflection}

\section{Resident Taught another Resident to do Haka}

Tom showed interest and respect for the Haka and said "I always wanted to learn the Haka". Jacob had Maori background, and respected others' culture as well as his own 
culture. Jacob might be encouraged that Tom wanted to learn the Haka. Jacob was probably empowered through teaching Tom. Their positive interaction might have strengthened the "brotherhood" or sense of togetherness among the residents.

\section{Group Consensus: Majority Won}

Lucy didn't want to learn an instrument. She is a quiet member in this group, and needs a long time to come up with ideas, so usually just agrees with others. Very often, while she is thinking, the other residents start their conversation, or propose their ideas. It probably gave Lucy no choice but to agree in the end. I was probably trying to run the group smoothly, because I was a little bit tense after Peter's nap, and Tom being upset. At that time, I probably didn't want new ideas to come out, instead, I wanted everyone to vote for the ideas, and then reach an agreement and finish. I was probably more aware of myself than the residents. Group consensus disadvantages minority group members. When we voted for ideas for open group, the majority of the group members agreed to learn an instrument, but because Lucy was the minority, her opinion was supressed.

\subsubsection{Things to Improve}

The open group seemed successful and fun, but it was hard to satisfy every member's needs and interests. I might ask the residents to decide on a plan for the open groups, and ask what they want to do in a particular session.

The preparation for the concert was fun and the residents were motivated, I realised it was important for them to organise "their concert". In the future, I will keep on asking the residents' feedback in the music therapy sessions. 


\subsection{CYCLE 6: PRE-CHRISTMAS CONCERT (THE THIRD CONCERT)}

\subsubsection{Planning}

The Pre-Christmas concert was to happen in the rehabilitation centre, and the staff members decided to use an outdoor garden space as the concert venue. It was necessary to advertise the concert for residents, staff members, and their families.

\subsubsection{Action}

\section{Interaction}

The concert was interactive and community-like right from the beginning.

Jacob and Frank did the Haka on their own. After that, the family members sang along while the residents were singing; clapping and praising after each song; laughing with the residents when it was humorous. One of the choir members volunteered to lead the drumming, and when it was finished the choir members went around and clapped hands with other concert participants.

It seems the choice of songs and musical activities encouraged interaction among the concert participants. As the Pre-Christmas concert happened before Christmas, the residents selected Christmas Carols. The residents also selected some Maori songs that are well known to New Zealanders. Family members probably had the natural response to sing along to the familiar music, which made the atmosphere friendly and community-like. The improvisation and drumming part encouraged individuals to take part and express themselves. Some residents, family members, and choir members volunteered to take part. Their courage to take part alone won admiration from the other participants. Their humorous and cheekiness made everybody laugh and made everyone more relaxed about the concert. The goodbye song aimed to encourage the participants to get to know each other, thereby helping the residents to branch out and meet people in the community. When they clapped hands, most of the choir members walked around, and the residents and family members sat still in their seats. The participants seemed 
happy to clap hands with others and finally know who they were making music with.

I announced the end of the concert, but it seemed that all the participants didn't want to stand up and leave. Therefore I played the piano accordion and walked inside to the dining area. Some of the residents and choir members got the message, and moved inside. However, the family members still sat outdoors. They had some bubbly in hand and chatted happily. It seems the concert created a socializing environment for the family members to gather and chat with each other.

\section{The Setting}

The Pre-Christmas concert happened outdoors, in a patio outside the dining area in the rehabilitation centre. There are some trees in the middle of the patio which divided the participants into three groups: residents, family members, and choir members. The trees were between the residents and family members, so residents and family members cannot see each other but the choir members can see everybody.

\section{“Drop-by" Concert Participants}

One resident Celeb, who usually doesn't participate in any other activities, came to the concert and sat all the way through beside the family members. When I clapped with him in the goodbye song, he was also tapping his foot to the music. It was very delightful to see him participating in an activity and enjoying it. Celeb seemed to have finally stepped out of his isolated life becoming closer with others.

The concert happened outdoors, so it allowed people to drop by and have a look. A resident, Heather, came by and saw the concert happening, she seemed to be surprised at what the residents were able to achieve. Two staff members also came and watched the concert. They chatted to each other and one of them nodded head to the beat of the music. They seemed to enjoy the music from the concert.

\section{Nervousness}

Some of the residents were nervous when performing, especially Jacob and Frank who 
began the concert with Haka. Frank's Haka went extremely fast so Jacob had difficult to follow. However, participants gave them a big clap. Tom played his keyboard solo, and was very relieved after his performance, wiping his forehead with his hand and saying "phew". Everybody smiled and then gave Tom an extra big applause for his courage to perform alone.

\section{“Improvisation" Could Lead to Fun}

We played the drums twice. Before we played, I asked a participant from the choir to demonstrate with me the play rule. The play rule was one person lead, and others follow. However, the choir member didn't understand the play rule and demonstrated in a confusing way. When we played the drum with all the participants, everybody ended up end up playing their own beats at the same time. They seemed to enjoy the different sounds from different percussive instruments, and enjoyed playing together. Towards the end of the concert, I invited the concert participants to stand up, and clap hand with other participants while we sing the goodbye song. I asked them to clap on the word "go". When we started singing, some participants and I walked around and clapped with other participants. I realised some of the participants clapped along the beat of the song, and some clapped to another beat. It seems that some of the participants found multitasking difficult, because they couldn't clap, sing, and look at other participants at the same time. However, the participants still smiled at each other, and seemed to enjoy the interaction.

\subsubsection{Reflection}

\section{Interaction}

Compared to the previous two concerts, the Pre-Christmas concert had a large number of family members. There were ten family members, more than ten choir members, more than ten residents and one staff member. It seems that the presence of the family members changed the milieu and encouraged the interaction among the concert participants. The family members warmly applauded after each song, and some of them said "wow, that was great", which probably encouraged the resident performers. It 
seems that the family members wanted to engage with the residents through music, and they sang along, and joined the drumming.

\section{Sense of Togetherness}

Through singing together, drumming together, clapping with each other, and laughing together, the concert participants probably developed a sense of togetherness as a whole. The seating divided the participants into three groups, each group can only see their own group most of the times. The seating probably helped each group to develop a sense of togetherness. The residents and the choir members performed as a group, which probably helped the two groups to develop a sense of togetherness.

\section{Choice of songs}

The residents decided the songs for the Pre-Christmas concert. The songs include Christmas Carols and Maori songs. The songs were familiar to New Zealanders, and probably resonated strongly on the resident performers' family members, as everyone started to sing-along. When I stepped aside from the leadership role and let the residents to suggest songs, I felt uncertain what songs the residents might came up with. As a matter of fact, I didn't need to worry because the residents' choice of songs was so good that everybody knew the songs and sang along to them. This re-assured me that the residents were capable of and were good at planning "their own concert".

\subsubsection{Things to Improve}

The Pre-Christmas Concert was almost the end of my placement in the rehabilitation centre. Also, some residents left the centre and went home for Christmas, so there weren't many residents around. We didn't have a "final product" such as another concert to work on; therefore the Music Therapy Sessions could focus on enjoyment, sharing, and interaction. Further, I could pass on the knowledge to staff members, so once I finished the placement, they could carry on with some of the activities from Music Therapy sessions or incorporate my knowledge into their practice. 


\subsection{SUMMARY OF ACTION CYCLES}

There were six action research cycles, each based on the previous cycles. Through the action research cycles, my thinking, my understanding about the residents, and my action improved. I thought we needed to be thorough prepared, musically, for the concert, yet through learning from the action cycles, I was able to realise the concert was about enjoyment and sharing, and I was able let go of the "music teacher" or "musician" role. I also initially thought I should be responsible for the concert, but I was able to let-go of the leadership role, to allow the residents to prepare for "their own concert". I assisted the residents to work together in groups, and I was able to realise that the residents needed to move from small groups to bigger group or even open groups, so that they will integrate better in the general milieu. 


\section{CHAPTER SIX: FINDING FROM SECOND INTERVIEWS}

\section{INTRODUCTION}

The second round of interviews was conducted after the Cycles of Learning. I invited the interviewees to give me their feedback on the music therapy service.

There were three resident interviewees and two staff interviewees. Both staff interviewees attended the first and the second (ECC concert), but not the third (PreChristmas) concert, therefore no data about Pre-Christmas concert were generated from the staff interviewees. However the resident interviewees attended all concerts, and were interviewed after the first and the third concerts. I expected the residents to generate data on all concerts, but in fact they talked about the concert closest to the interview in time. Accordingly, data was generated from the resident interviewees on the first and the third concerts.

\subsection{CATEGORIES FROM THE END INTERVIEWS}

There were several categories generated from the Second Interview. The categories are listed below:

-Background

-Residents Engagement in Music Related Activities

-Music Related Activities Encouraged Positive Musical Interaction

-Music Related Activities Encouraged Positive Social Interaction

-Residents' Understanding of Interaction Improved

-Residents Had Different Ideas Regarding How They Felt About Living With Others

-Staff Suggested Music Could Improve interaction through distracting people from conflict

-Some of the Residents Isolate Themselves And Have No Sense Of Community -Music Related Activities Reduce Learned Helplessness 


\subsection{EXPASION ONCATEGORIES FROM THE SECOND INTERVIEW}

\section{Background}

There were five interviewees. All three resident interviewees, Jacob, Iris and Peter, attended all the concerts that were held in the rehabilitation centre. Both staff interviewees, Susan and Abby attended the first concert, and the ECC concert, but not the Pre-Christmas concert.

\section{Residents Engaged in Music Related Activities}

The residents engaged in music related activities such as listening to music, participating or performing in concerts, and joining music related activities. The interviewees said they enjoyed the music, the social interaction and musical interaction. These music activities inspired the residents to "branch out" to interact with other residents or into the community. One resident interviewee Peter said many residents listened to music in their own rooms, but other residents who passed by could over-hear the music. Peter explained "music starts in your room, shouldn't it". Another interviewee said after attending the Pre-Christmas Concert, she wanted to join a choir and "branch out and meet other centres".

\section{Music Related Activities Encourage Positive Musical Interaction}

There were some positive musical interactions in music related activities. All the interviewees identified that music listening and concert participation encouraged interaction among the residents or between the communities. The residents suggested that they had more fun in the Pre-Christmas concert compared to previous concerts because there was more interaction. The music related interaction in the Pre-Christmas concert included playing drums and improvisation.

\section{Music Related Activities Encourage Social Interaction}

All the concerts that happened in the rehabilitation centre involved participants in the 
centre and from the community. The participants were: rehabilitation centre staff members and residents, family members, plus ECC teachers and children or Church choir members. In the first concert and ECC concert, the number of family members was small, but in the Pre-Christmas concert, the number of family member was large. The presence of Family members and Church choir members encouraged the positive social interaction, because they seemed to understand the needs of the residents. Two out of three resident interviewees identified the benefit of family participants or Church choir member participants. Resident interviewee Jacob said that the family members "understand what this (the concert or the performance) is all about"; and another resident interviewee Peter said "I remembered the big smile, the big handshakes (from the Church choir members)... I tried not to give anybody a cuddle".

\section{Residents Improved Their Understanding of Interaction}

Two resident interviewees realised the importance of talking and listening in return. In the first interview, resident interviewee Peter said he appreciated my way of giving resident equal attention, that I "treated everyone individually a bit". However, Peter didn't realise that was also what the residents need to do. Resident interviewee Iris identified that residents were talking at the same time. In the second (end) interview, another resident interviewee Jacob said that in order to play the drum together, they need to listen to the lead drummer; and they should listen to the songs first before they started singing. Jacob had the understanding "equal attention" or "mutual respect", and he said listening to each other's choice of songs is “just like give and take". Resident Iris mentioned the way of interaction in 'Travel the world group', when some people dominated the talking, it made her feel the session was long. However, she didn't mention whether the residents were talking at the same time. It seems that interviewees might have improved their thinking or action about 'one person talking at a time'.

\section{Residents Had Different Ideas on How They Felt about Living with Others}

There were three resident interviewees in both interviews. In the second interview, two resident interviewees identified living with others is "no problem"; but only one resident interviewee identified it as "quite hard". 
Staff suggested music can improve the interaction through distracting people from the conflict

One staff member said listening to soft-background music can possibly distract residents from their conflict while they are eating meals.

\section{Some of the Residents Isolate Themselves and Have No Sense of Community}

Both staff interviewees and one resident interviewee identified that there is a small group of residents who are "soloists" in the centre. There was a large group of residents who mix better with others. The groups were separated by mental ability. Those who had a higher cognitive ability chose to isolate themselves, and preferred to interact with staff members because they thought their cognitive level was the same as the staff members'. On the other hand, the residents who have low cognitive functioning were more sociable, plus the programs in the centre were designed for them because they were the majority.

\section{Soloist Residents 'Became the Star'}

Resident Peter was identified as a soloist in the centre, both by the staff interviewees and by himself. When he brought a CD to listen with the other residents, he took the spot light on that day. Peter said: "a lot of people asked me what that was (the CD he played), it was quite up-lifting, quite a cheer up, somebody liked my old music".

\section{Soloist Resident Joined the Concert}

One resident, Celeb, usually stays in his room, but came to the Pre-Christmas concert. Staff interviewee, Susan, said that the music therapy led to a break though. That is, it was exciting for him to participate in social activities.

\section{Music Related Activities Reduce Learned Helplessness}

Music related activities probably reduced learned helplessness in residents. Resident interviewee, Peter, was able to value the resident input. He identify that the residents 
were well prepared for the Pre-Christmas concert, and what they've done "fit the bill, which means good enough". Resident Jacob was able to see his input for the outdoor concert: "it feels like you've given it a lot", and he said that the residents achieved something: "we did quite a lot of good things like the drum beats (in the Pre-Christmas concert)". He seemed to improve on the feeling of learned helplessness through the concert; however, he still said that he couldn't change the environment in the centre.

\subsection{SUMMARY OF FINDINGS FROM THE SECOND INTERVIEW}

All the resident interviewees attended the Pre-Christmas concert and enjoyed the musical and social interaction in the concert. The concert may have inspired the residents to "branch" out into the community. The residents seemed to improve on their understanding of interaction in music, and stated that they had to listen to each other in order to play the drum. The residents seemed to improve on their way of interaction in the music. The interviewees identified that there were "socially isolated" individuals in the centre, and they were delighted to know that one of the "socially isolated" individual attended the Pre-Christmas concert. The participants didn't comment much on the ECC concert because it occurred long before the second interview was conducted. 


\section{CHAPTER SEVEN: ANSWERS TO THE RESEARCH QUESTIONS}

\subsection{WHAT MUSIC THERAPY STRATEGIES DID I USE}

Music Therapy Strategies are the strategies "used by the therapist to engage the client in a specific aspect of the therapeutic process; or to accompany a specific methodological objective" (Brusia, 1987, cited in Rickson, 2010b)

In this research, the main music therapy strategies or approaches were: moving residents from small groups, to larger groups, to open groups; helping residents to prepare for and perform in a concert; and making links and collaborating with other community groups. Further, in each approach, I used interactive songs or musical activities, includes leadfollow drumming, conductor-band game, improvisation, turn-taking songs, call-andresponse songs, and two-part songs.

\subsection{HOW DID THE MUSIC THERAPY STRATEGIES IMPROVE THE MILIEU}

These Music Therapy Strategies helped the residents to be together, work together, and enjoy the music together. The Strategies also helped the residents to improve ways of interaction.

The concert gave the resident performers a chance to perform, which improved their confidence and therefore empowered them. Performing together also helped the residents to form sense of togetherness. The concert gave the resident audience a chance to enjoy the music, and brought in people from other centres. The concert re-created the community and gave the residents a chance to interact with people from outside the centre. This might be a step towards stepping into the community. This was re-enforced by one resident's comment that she wanted to "branch out" into the community. 
The Music Therapy sessions encouraged positive and mutual interaction among the residents, helping them to develop musical skills which in turn helped them to perform in the concerts. The interactive songs and musical activities encouraged positive social interaction, which hopefully will influence residents' behaviour either subconsciously or consciously. Well-known songs encouraged the concert audience to sing along to the performers, and are especially good when sung at the concerts, where the performers don't know the audience and felt anxious to perform. 


\section{CHAPTER EIGHT: DISCUSSION}

\section{INTRODUCTION}

This chapter contains five parts: Discussion of Findings in Relation to the Literature; Methodological consideration; Further Research; Implication for other Music Therapists; and Significance of the Research.

\subsection{DISCUSSION OF FINDING IN RELATION TO THE LITERATURE}

\subsubsection{Music Therapy Strategies Empowered the Institutionalised Adults}

Residents who live in institutions have limited autonomy. The residents living in the institution might have developed learned helplessness. Learned helplessness is a psychological state that people have acquired from the environment they live in, which prevents them from feeling self-mastering (Seligman, 1975). People who experience learned helplessness believe that they have low ability but the environment or therapist has high ability. They feel their own input is not attributed to the outcome, but the environment or the therapist's input is attributed to the outcome.

Long-term institutionalization and learned helplessness seemed to lead to the residents' lack of motivation and initiation. The residents depend on the staff members in daily activities, which was likely to reinforce the residents' feeling of learned helplessness. The residents demonstrate learned helplessness through lack of commitment to the sessions, lack of suggestions and motivation to interact during sessions.

Music therapy strategies empowered the residents $t$ giving them choice, giving them an opportunity to perform, and empowering them to plan for their "own" concert. The residents were empowered because they had the choice of joining the music therapy sessions. Ansdell (2010) suggested that the residents living in the rehabilitation centre 
didn't have much choice of who is around, but they did have the choice of coming to music therapy sessions or other activity groups. When they join the music therapy sessions, they form a mini community, or a "music community", in the centre (Ansdell, 2010).

The residents were also empowered because they were able to perform in front of the audiences. In particular, some of the audiences were the residents' therapist, caregivers, and family members. The residents' role changed from a dependant who received care; to a "musician" who give joy. The residents who performed in the concert were likely to have improved confidence. However, the concert should have an emphasis on "sharing" rather than "performing"; otherwise the residents are at risk of being judged on their music abilities, which could disempower them.

Furthermore, the residents were empowered through participation in the planning of the concerts. The residents, who had low motivation to join the music therapy sessions, showed high motivation after they were able to choose the songs for "their concert". The high motivation arose under a certain context: the concert they were planning for was the Pre-Christmas concert, which was also near the end of my music therapy placement. The residents probably realised that they should "make use of" the music therapy service, or were influenced by the knowledge that their family were coming to the concert.

During the research, I changed my leadership style from strong to supportive. I had strong leadership style in action research cycles one and two, and the residents showed lack of motivation, and gave all the credit to me for their success. When I stepped aside from the leadership role in action research cycles four and five, the residents were able to understand that their actions had consequences, which helped them to developed realistic sense of self-mastery (James, 1987). It is supported from the observation that the residents were more motivated and had more ideas in preparation for "their own concert". The residents were able to give credit to the other performers and themselves. 


\subsubsection{Open Groups Can Help the Residents to Adapt To Changes in the Milieu}

Open group work is beneficial for residents to adapt the changes in the environment, and prepare them for integrating into the community. Wood (2006) suggested community music therapist working through four stages to help the residents to reintegrate back into the community: individual music therapy sessions, group music therapy sessions, open groups such as music workshops, and then concerts (Wood, 2006). In open groups, the residents can choose to commit or participate any time they like. So each time, in an open group, the participants are different and the group interaction is different (Pavliecevic, 2003). This allows the participants to adapt to changes in the groups, and helps them to adapt to the changes when they interact in the rehabilitation centre. However, to achieve this, the members have to identify the problem, understand it, believe it's solvable, and be motivated to solve it (Levi, 2011). Residents understood that they have problem with interaction, but they don't seem to understand the cause of the difficult interaction, or believe they can solve it.

Groups can have three different forms, closed, semi-open or open group. The forms of group have an impact on personal and musical interaction of the residents (Pavlicevic, 2003). In closed groups, the residents are committed to attendance and goals. In open groups the residents don't have to come to the sessions, which might benefit the institutionalised adults by giving them choice and opportunity for empowerment. The semi-open group has both regular attendants and irregular attendants (Pavlicevic, 2003).

In this research, the residents started to join each other's sessions and formed semi-open groups during cycle four. The group dynamics changed when new-comers joined in a group, which will be discussed later.

The open group happened in cycle five. At this point I realised I needed to use a different leadership style: in closed groups, I didn't need to be very directive; however, in open groups, I needed to be very directive. In a large group situation, clear instructions might help to reduce the anxiousness of the group members. This idea mirrored Wood's suggestion (2003) that Community Music Therapy requires more structured Music Therapy Strategies. 


\subsubsection{Group Dynamics Was an Important Part of Working with Music Therapy Groups}

\section{Group Process}

In this research, I helped the residents to work together, and aimed to change their behaviour in the hope that the changed behaviour can be transferred into daily lives, through the use of group work. Lewin (1951, cited in Levi, 2011) believes that changing the behaviour of members in a group can promote social changes. Lewin believed that when group members step out of the therapy room into the general environment, the members are likely to reinforce or stabilize their changed behaviours. In contrast, when only one individual changes his behaviour in the therapy room and steps into the environment, he is likely to revert to the previous behaviour, and cannot promote social change (Levi, 2011).

Groups mainly engaged in two types of activities: making decisions and performing tasks. The activities were influenced by internal group process. Group process contains five stages as stated by Tuckman and Jensen (1997, cited in Levi, 2011). The stages are forming, storming, norming, performing, and adjourning. Forming is when the members get to know one another; storming is when the members have conflicts on group roles and procedures; norming is when members establish group rules and social relationship; performing is when members work on the tasks and adjourning is when the task is finished and the group ends. The music therapy sessions happened for six months before the research started, therefore the early stages of group process were not observed in this research. However, in cycle four when the residents were preparing for the concert and re-grouping into open groups, the group restructured and established new group norms. The group norm is the unspoken group rule of appropriate or inappropriate behaviours (Levi, 2011). The existing inappropriate group norms among the residents include name calling and talking at the same time. Those who attended regularly had developed a strong bond with each other, and together had developed their own group rules. This was a barrier to others who want to join them, as well as isolating those who are currently in it. When I clearly stated the group rules and norms, the residents were more able to work together. When I did not, the residents were unable to work together, and got stuck in the 'storming' stage of group process 
Another group theorist Bion (1961) argues that in each group, there are two dimensions of behaviour: the work group and the basic assumption group. The work group understands individual needs, sets goals and aids development. However, the basic assumption group works under assumptions and the group members prevents development and change (Bion, 1961). In cycle four of this research, when the new comer joined in, existing members articulated their rules and told off the newcomer. Existing members were protecting their group identity and resisted changes. Jacobs and Spradlin said (1974) the success of the small group may not lead to success when integrating in the general environment. Once I realised this, I decided it was time to regroup the residents into larger groups.

According to Lewin's (1951, cited in Levi, 2011) behaviour transference theory, through sharing the experience of singing and using conversation courtesy in the group, residents might continue to reinforce conversation courtesy and start listening to each other upon returning to the rehabilitation centre. In this research, the residents were expected to show improved to show conversation courtesy and reduced naming calling. However, the improvement in conversation courtesy was only seen in the group but not observed among when residents interact in the centre. This might partly because I was not always in the centre, and partly because they need longer time to change this behaviour.

\subsubsection{Music Therapy Strategies Improved Sense of Belonging:}

Joining group creates a sense of belonging in the members (Levi, 2011). Performing as a group in the presence of other groups can strengthen the sense of belonging among the overall group. In addition, positive communication can strengthen the sense of belonging (Levi, 2011). Elefant (2010) facilitated the group process of two groups of children to encourage the successful inclusion of the special education children. In the early stage of inter-group process, the dissimilarities between the two groups could cause a process of collectiveness and togetherness in each sub group. When the residents performed with people from early childhood centre during the first and the second concerts, they probably developed stronger bonds among themselves as 'resident performers'. This idea is supported by the fact that the residents performers sat together 
after the first concert. However, the residents did not necessarily develop the bond within the rehabilitation centre or the community, but with the performance group. The residents also identified themselves as 'us' and 'we' when they talk about the performance together as a group.

Elefant (2010) observed similar interaction among the performance group, and stated that difference between two groups might prevent the two groups to bridge the gaps and form one big group. To bridge the groups require both groups to step out and assimilate the differences, resulting in a feeling of togetherness (Elefant, 2010). The residents probably developed a sense of belonging to the centre or community during the third concert, the pre-Christmas concert. The residents, family, and choir members all stepped out, interacted with others, shared nervousness and humorous with others and made connection with others. They seemed to be more familiar with each other and to have developed a sense of togetherness.

\section{Belonging to a Music Group}

The residents seemed to develop a sense of belonging to the group of "resident performers". In each concert, the residents sat together. The seating was arranged by the staff members, probably because it was easier to organise. The residents therefore were "physically together during the concerts. However, there is a question of whether the residents felt they belonged to the group or were "emotionally together", because the observations at each of the three concerts were different.

I observed the interaction of residents after each concert. After the first concert, the residents sat together at one dining table, chatting and waiting for lunch together. The context for the first concert was: it was situated in the rehabilitation centre, and the concert venue was close to the dining area. In contrast, after the ECC concert (second concert), most of the residents went to their own flat; and in the dining area, one resident gave another resident negative comment. The context for the ECC concert was: it was situated in another centre; ECC, and the residents were probably tired from the travelling therefore they went to their rooms, and due to their tiredness they were grumpier. The Pre-Christmas concert (third concert) probably encouraged a sense of belonging among the residents' family members, as well as the whole centre. The context to the Pre-Christmas concert was: it happened in an outdoor patio in the 
rehabilitation centre, and after the concert, all the residents went to the dining area to have lunch. The residents sat at their usual seats, so the sense of togetherness was probably developed but not observable due to the seating. After the concert, the family member sat together, and chatted happily. The concert seemed to have encouraged the sense of belonging among the family members of the residents.

\section{Belonging to the Centre}

In the interviews, interviewees identified the residents had sense of belonging to the rehabilitation centre. The centre is the residents' home that they have lived for about ten years; and some of the resident interviewees enjoyed interacting with friends who also live in the centre. These residents seemed to feel that they belong to this centre. However, interviewees identified that a small group of the residents chose to isolate themselves. They had higher cognitive levels and didn't see themselves at the same level as other residents. This means they don't feel that other residents belong to the same group as them. They also don't engage in the same activities as the other residents. However, one of these "isolated" residents chose to join the Pre-Christmas concert, and this "break-through" could probably improve his sense of belonging to the centre.

\subsubsection{Recreation of Community}

Music mediates the interaction of between people and groups. Ansdell (2002, cited in Wood, 2003) stated that "the main agenda of Community Music has been the recreation of community by providing opportunities for musical participation. The discourse is often a social and political one, setting an agenda for work with geographically or socially defined groups who suffer marginalisation. An important strand of this thinking considers how the individual and the group relate in contemporary society and what role music-making has in the changing relationship between them". Wood (2006) experienced performing with his clients in a church, and he said the experience was both a community and religious experience. 
Music Therapy Sessions Created Sense of Community:

The Music Therapy sessions were over-heard by staff members and residents who passed by; and the session participants talked about the sessions outside of the music therapy sessions. One resident, in particular, was invited to join the Music Therapy sessions by other residents. The Music Therapy sessions encouraged the social bond, or the sense of community in the centre.

\section{Concert Recreated Community:}

The concerts were able to re-create community within its venue. All of the three concerts involved participants from the rehabilitation centre and people from other centres. Being together and making music together helped to re-create the community. The Pre-Christmas concert in particular helped the residents, family members, and church choir members, to make music, share the sense of humour in the music, and get to know each other in the music. All the participants seemed to enjoy the chance to be together and have music in a family or community like event. Our music and laughter even attracted other residents and staff members to join us. One resident and three staff members dropped by and enjoyed watching the concert. Celeb who is usually "isolated in his own little world" joined the Pre-Christmas concert and sat all the way through the concert. The open venue helped to create this open and inviting atmosphere. This reflects what Pavlicevic said about community music therapy, that music naturally radiates and attracts people, and music is not only designed for private enjoyment (Pavlicevic, 2004)

\section{Concert helped Residents to Integrate into the Community}

The first concert seemed very successful, because after the concert, the audience wanted to organise more concerts. One of them was a resident's sister, who plays ukulele in a ukulele band. Another one was the manager of the Early Education Centre. The second concert was organised by ECC through the collaboration between ECC and the rehabilitation centre. I felt it was a social interchange, that if rehabilitation centre invited other centres, they might invite us in return. This way, we might help the residents to step into the community. 
Iris identified that she enjoyed the Pre-Christmas concert most of all because more interaction occurred when people from other centres came. She said the concert helped the residents to "branch out", she expressed willingness to join a choir; and she said the residents can "go on tour and visit other centres, because it brings another atmosphere".

\subsubsection{Traditional or Community Music Therapy}

In this research, my community music therapy practice included therapy group, open group, and community concerts. The focus of the music therapy practice in my research gradually moved from traditional 'closed-door' music therapy to community music therapy. Action research cycles one and two were 'traditional music therapy groups'; action research cycles four and five were 'open groups' and action research cycles three and six were 'community concerts'.

In action research cycles one, two, four and five, therapy session shifted from traditional 'closed-door' to 'open' groups. This shift followed client needs of making music with other residents in the centre.

However, in the public concerts, there were issues about residents' privacy and confidence. In the first concert, one resident's name was mentioned by another resident without permission and the solo residents' music skills were judged by the audience and me. The public concerts brought in 'strangers' and made the residents vulnerable. Some music therapists would be uncomfortable with calling this 'music therapy', because it puts the vulnerable residents in danger of being judged and disempowered. On the other hand, the second and third concerts were well planned, focused on the music making process, and provided residents a chance to make music and interact with people in the community, and that is something they do not usually do. The residents were empowered through the second and third concerts. Music was the tool for establishing the connection, to achieve community wellbeing, and was thus community music therapy (Ansdell, 2005). 


\subsubsection{The Research Changed My Thinking}

I went through music training, and my 'perfectionistic' values influenced my practice. When I organised the concerts I was anxious to perform perfectly. I asked the residents to practice repetitively before the concert, while they thought that they were already good enough. Practicing over and again probably disempowered the residents.

Furthermore, during the first concert, I even corrected a resident performer's mistake when he finished playing. I emphasised his playing on the 'wrong keys' while he had great courage to step up and perform for audience. At this point, I realised that I should encourage the enjoyment and sharing rather than the consequence of good or bad. However, while preparing for the second concert, I still held the 'perfectionism' view and asked the residents to practice repeatedly. Through the residents' reflection prior to the second concert, I realised I should focus on 'enjoyable and interactive music' rather than 'perfect music'. Because of this change, when we prepared for the Pre-Christmas concert, I was more at ease, because it was the "residents' concert" and also a "sharing concert". Instead of worrying about the consequences, I cared about the enjoyment and interaction. As a consequence, the residents enjoyed planning and performing in "their concert", and felt less pressure of being judged on music skills.

\subsubsection{Summary}

Music Therapy Strategies helped the residents to interact and work together in the Music Therapy groups, by changing the residents' thinking about how they need to listen in order to play the instruments. This research did not study how the interaction skills could be generalised into daily lives, but in the hope that the musical interaction influenced the residents' thinking and how the way they act subconsciously. Music Therapy Strategies empowered the residents, by giving the residents choice, valuing their input, and allowing them to plan for and perform in their own concerts. However, I should be very careful not let the residents compare music skills or be judged on their music skills. Music Therapy may have improved the sense of belonging and sense of community. Through these changes, Music Therapy Strategies may have improved the general milieu in a rehabilitation centre. 


\subsection{METHODOLOGICAL CONSIDERATIONS}

\subsubsection{Research Design: Action Research}

This study involved Action Research. I studied my own practice, with a view to improving what I do. This research is guided by my own values, includes choice of literature, choice of strategies, my way of thinking, and my way of action. My values changed during the research, from 'music has to be perfect, and the residents' performance needs to be good', to 'music encourages interaction and socialization'. From 'I want to prove community music therapy is good' to re-define and question whether it is sensible to change people's home environment. From 'I'm the leader and I need to organise a good concert for the residents' to 'it is the residents' concert and I will help them to enjoy it'.

\subsubsection{Limitation On Data Collection: Interview Participants}

The interviews generated rich data because the residents talked about every aspect of their lives, which is relevant to the general milieu in the centre. The end interview happened following the Pre-Christmas concert. The end interview therefore generated rich data on the Pre-Christmas concert. However, the ECC concert happened in the middle of the research, and so all the interviewees couldn't remember much detail from the ECC concert. If there were three interviews following each concert, the study might have generated more findings on the ECC concert. Further, two staff interviewees didn't attend the Pre-Christmas concert, therefore the findings of the Pre-Christmas concert based solely on the resident interviewees.

\subsubsection{Limitation on Data Analysis: Thematic Analysis}

Doing Thematic Analysis is an interpretive process. This process generates meaning, by inventing or developing knowledge and constructing theories (Diesing, 1971, cited in Strauss \& Corbin, 1990). This interpretive process however has two limitations. First, Thematic Analysis was influenced by the researcher's own values and literature study. I used my "concept pool" to label the Concepts, and interpreted meaning of these concepts and grouped the concepts into Categories, and I used my "concept pool" to 
name the Categories. The whole process is based on what I think from the data.

Further, the finding from the Thematic Analysis is limited to what I found from the data: the Categories and their descriptions, and the way I integrated the data into Categories. What I did not find is a limitation to this study. The reason was either that I didn't collect enough or didn't collect the right kind of information or that my Categorization process was not quite right (Strauss \& Corbin, 1990).

\subsubsection{Peer Debriefing}

Due to the time frame of the research, I could not use peer de-briefing throughout this research.

Peer de-briefing is used in qualitative research to improve research credibility (Barber \& Walczak, 2009). Peer de-briefing provides a second opinion, and improves the reflexivity on the research. Peer de-briefing can be involved in method design, data collection, and data analysis process. It is very important to involve peer-debriefing in Grounded Theory analysis as researcher used high level of interpretation during this process (Strauss \& Corbin, 1990).

\subsubsection{Re-define the Word Milieu during the Research}

During the research, I felt the need to clarify the concept of Community and Music Therapy and to re-define the word Milieu. Aasgaard (2001) wrote that environment is the external condition in which a person lives, but the milieu means the immediate environment a person encounters. Aasgarrd's work was based on music environmental therapy, and he states the goal should no longer focus on the individual clients, but should be extended to encompass all present in a defined milieu.

The definition change lead to the change in focus of the research. In the first Interview, I defined the word Milieu as "human environment" for the interviewees. In the second (end) interview, I defined the word Milieu as "sense of belonging and sense of community" for the interviewees. The interviewee's conversation might have changed because of the different explanation. However, the use of semi-open interview questions probably still generated rich data. During the first three action cycles, I focused my observation and reflection on the "interaction" of residents; and during the last three 
action cycles, I focused my observation and reflection on the "sense of belonging and sense of community". The definition of the word influenced the focus of the research.

\subsection{FURTHER RESEARCH}

\subsubsection{Data Collection: Systematic Observation and Reflection}

In this research, I observed the music therapy group sessions and social situation such as the concerts. I observed the music and social interaction in the group member, based on the learning from Music Therapy training and literature of Group Dynamics. However, social situation like the concert generated large amount of information, and I felt I was in a mist to record everything that I observed.

Other researchers suggested observation guideline for Community Music Therapists. Warner (2011) said that there might be a need to observe and analysis in the large group situation. She states that Music Therapists has been neglecting the analysis of large group situation and believed it should be embraced by community musicians. As Stige and Ansdell have developed Community Music Therapy, music therapists should think about large groups in practice. Warner suggested several theories to analyse the large group situation: Group Dynamics, Group Analysis, and Process Perspective theories. Group Analysis theory is informed by psychoanalytic thinking and focused on belonging and socialization. In contrast, Process Perspective theory focuses on interaction and behavioural changes among the members.

Wood (2006) developed a Community Music Therapy Rating Scale based on the traditional Nordoff-Robbins Rating Scales. He focused on observing participants' independence and interdependence ability. He states that Community Music Therapists should focus on the Interdependence ability, which includes participants' willingness to work in a social setting; responsibility for shared musical work, and full collaboration.

\subsection{2"Real Life Music" Re-wires the Brain}

This research studied how music therapy strategies can improve the milieu, and it focused on the interaction among the residents, and the sense of belonging. Both staff members and residents identified that the brain injury in some of the residents lead to 
their difficulties in interaction. Therefore I will be interested in further research on how community music therapy can improve the interaction among the people with brain injury.

Recent research, Fogg and Talmange (2010) suggested singing in a community choir might help the brain to "rewire". The choir members consist of volunteers of neurological damaged adults. The research suggested possible improvement in the choir members' concentration and speech fluency.

Altenmuller (2004) suggests that music has an effect on the brain and on people's social interaction. He emphasised that the effect of music cannot be studied in laboratory alone, but need to be studied in the context, because the "real life music" draws on widespread parts of the brain, in unpredictable ways, and in ways that are adapted to each individual in their context.

\subsubsection{Milieu Music Might Be an Interesting Topic in Further Research}

In this research, I focused on what I can "do" to change the residents' way of interaction and what I can "do" to change the milieu. I focused on music therapy strategies like songs, sessions or concerts. When I put on the CD at lunch time, I observed the change in the atmosphere, especially when the music was very enjoyable or very annoying. Therefore, milieu music or environmental music also had impact on the general milieu in the centre. The response from the residents or staff members was different. Some residents enjoyed providing the $\mathrm{CD}$, and others enjoyed listening to the music. Some residents think it's annoy and one staff member said, music needs to be soft and relaxing, therefore to help the residents concentrate on the meals.

Ayres (1987) researched the effect of background music on elapsed feeding time. The results showed non-contingent background music increased the elapsed feeding time. Ayres interprets that music helped teachers and student to relax, and music might eliminate the unpredictable noise in the dining area. Cohen and Lezak (1977) states that music repeatedly stimulates the auditory system, which helps the listener to desensitize 
to the short, unpredictable environmental noises, therefore increase the listener's attention (as cited in Ayres, 1987).

\subsection{IMPLICATION FOR OTHER MUSIC THERAPISTS}

Research happened in a rehabilitation setting, which is also a residential setting. The general milieu is good and friendly; however, conflicts between residents arose because of their disability and institutionalization. The research might be applicable to other music therapists with careful consideration to the context.

\subsection{SIGNIFICANCE OF THE RESEARCH}

The research enabled me to improve my own practice; therefore it might enable other music therapists to improve their practice. Although the results will not be generalizable, they are likely to be of interest to other music therapists, especially to those who work, or want to develop work, in rehabilitation centres. There is limited music therapy research describing music therapy within rehabilitation communities, and community music therapy itself is relatively new. The findings are therefore likely to be of value to music therapy and rehabilitation communities. 


\section{CHAPTER NINE: CONCLUSION}

This research aimed to find out how I might use music to enhance the general milieu in a rehabilitation centre. It involved action research cycles to improve my thinking and in turn my Community Music Therapy practice.

The cycle of learning led to the introduction of more 'open' group work and the use of the 'concert' to encourage interaction and social integration. The open groups helped the residents to adapt to change, and to develop positive social interactions thereby preparing them for working with others in different contexts. I developed my leadership skills by adjusting the levels of direction and support that I was able to offer residents in various contexts. The residents moved from 'passive participants' to 'active participants' while they prepared for the concerts, and engaged in the process of gathering ideas, making decisions, and teaching each other music skills. I relinquish my role from 'music teacher' to 'concert assistant' and empowered the residents to prepare for their own concert. The residents also experienced a sense of togetherness and community while participating in the concert, and were willing to share their music with the wider community.

This qualitative action research project is highly influenced by my values and my interpretation of the data. Therefore the research cannot be generalized. However, the research can inform other music therapists as there is little research done in the area of Community Music Therapy practice based in rehabilitation centre. Further research could include the development of data collection and analysis tools for Community Music Therapists; study of how concerts and singing can improve the interaction among brain injured participants; and studying how the environmental music can improve the interaction among participants. 


\section{REFERENCES}

Aasgaard, T. (1999). Music Therapy and the Creative Act. In D. Aldridge (Eds.), Music Therapy in Palliative Care: New voices (pp. 15-28). London: Jessica Kingsley Publishers.

Ansdell, G. (2010). Belonging through Musicking: Explorations of Musical Community. In B. Stige, G. Ansdell, C. Elefant \& M. Pavlicivic (Eds.), Where Music Helps, Community Music Therapy in Action and Reflection (pp. 41-46). Great Britain: Ashgate Publishing Limited.

Ansdell, G. (2005). Being Who You Aren't; Doing What You Can't: Community Music Therapy \& the Paradoxes of Performance. [online] Voices: A World Forum for Music Therapy. Retrieved June 11, 2010, from http://www.voices.no/mainissues/mi40005000192.html

Ansdell, G. (2003). Community Music therapy: "Big British Balloon” or future international trend? In Community, relationship and spirit: continuing the dialogue and debate (pp. 1-14). London: BSMT Publications

Ansdell, G. (2002). Community Music Therapy \& The Winds of Change. [online] Voices: A World Forum for Music Therapy. Retrieved June 11, 2010, from http://www.voices.no/mainissues/Voices2(2)ansdell.html

Altenmuller, E.O. (2004). Music in Your Head. Scientific American Mind, 14 (2), 24-31. Ayres, B. R. (1987). The Effects of a Music Stimulus Environment Versus Regular Cafeteria Environment During Therapeutic Feeding. Journal of Music Therapy, 24 (1), 14-26.

Barber, J. P., \& Walczak, K. K. (2009). Conscience and Critic: Peer Debriefing Strategies in Grounded Theory Research. Annual Meeting of the American Educational Research Association. San Diego, California. 
Baker, F., \& Tamplin, J. (2006). Music Therapy Methods in Neurorehabilitation: A Clinician's Manual. London: Jessica Kingsley Publishers.

Bion, W.R. (1961). Experiences in groups. London: Tavistock Publications.

Bradt, J. ,Magee, W. L., Dileo, C., Wheeler, B L., \& McGilloway, E. (2010). Music therapy for acquired brain injury (Review). The Cochrane Collaboration.

Bruscia, K. (1998). Defining music therapy (2 ${ }^{\text {nd }}$ ed.). USA: .Barcelona Publishers.

Christopher, J.C., Madden, M., \& Potts, L. (2007). Towards understanding community: people and places. Great Britain: Palgrave Macmillan.

Clair, A. \& Pasiali, V. \& LaGasse, B. (2008). Neurologic Music Therapy. In A. Darrow (Eds.), Introduction to Approaches in Music Therapy (2 ${ }^{\text {nd }}$ ed.), (00. 153-172). USA: Silver Spring.

Crotty, M. (1998). The foundation of social research: meaning and perspective in the research process. St Leonards, NSW: Allen\& Unwin.

Croxson, M., Donaldson, G., \& Parsons, G. (1989). Music Leadership in Community Workshop Notes. Music in the community conference paper 1989. Palmerston North: Organising Committee of Music '89.

Daveson, B.A. (2008). A Description of a Music Therapy Meta-model in Neurodisability and Neuro-rehabilitation for use with Children, Adolescents and Adults. Australian Journal of Music Therapy. 19( ), 70-85.

Department of Education. (1988). Music and community: Discussion paper. Wellington, New Zealand: Department of Education.

Elefant, C. (2010) Reflection: Musical Inclusion, Intergroup Relations, and Community Development. In B. Stige, G. Ansdell, C. Elefant \& M. Pavlicevic (Eds.), Where Music 
Helps: Community Music Therapy in Action and Reflection (pp. 75-92). Great Britain: Ashgate.

Fogg, L., \& Talmage, A. (2010). The CeleBRation Choir: Establishing Community Music Therapy for People Living with Neurological Conditions. 2010 Music Therapy New Zealand Conference. Christchurch, New Zealand.

Geldard, K., \& Geldard, D. (2001). Working with Children in Groups, A Handbook for Counselors, Educators and Community Workers. Great Britain: Palgrave publisher.

Hunt, M. (2005). Action Research and Music Therapy: Group Music Therapy with Young Refugees in a School Community. Voices: A World Forum for Music Therapy. Retrieved June 11, 2010, from http://www.voices.no/mainissues/mi40005000184.html

Jacobs, A., \& Spradlin, W. (1974). The group as agent of change. New York: Behavioral Publications.

James, M.R. (1987). Implication of selected social psychological theories on life-long skill generalization. Music Therapy Perspectives, 4 ( ), 29-33.

Johansson, B.B. (2011). Current Trends in Stroke Rehabilitation. A review with focus on brain plasticity (review article). Acta Neuraol Scand, 123 ( ), 147 -159.

Kenny, C., \& Aigen, K. (2006). Music \& life in the field of play: an anthology. Gilsum, NH: Barcelona Publishers.

Levi, D. (2011). Group Dynamics for Teams. United States of American: SAGE Publications Inc.

McArthur, J. (2009). Learning Better Together: Working Towards Inclusive Education in New Zealand Schools. Wellington, NZ: IHC. 
McNiff, J., \& Whitehead, J. (2010). You and your action research ( $3^{\text {rd }}$ ed.). London: Routledge.

Minahan, M., \& Hutton, C. (2004). Group development: meet the theories. Retrieved on October 20, 2011, from www.ntl.org/upload/2004_ODN_Conf_Proceedings.

Music Therapy New Zealand. (2011). About Us. Retrieved from: http://www.musictherapy.org.nz/about-us/

O’Grady, L., \& McFerran, K. (2007). Community Music Therapy and Its Relationship to Community Music: Where Does It End? Nordic journal of music therapy, 16(1), 1416.

Pavlicevic, M. (2004a). Introduction: "the ripple effect". In M. Pavlicevic \& A. Gary (Eds.), Community music therapy (pp.15-34). England: Jessica Kingsley publishers.

Pavlicevic, M. (2004b). Learning from Thembalethu: Towards responsive and responsible practice in community music therapy. In M. Pavlicevic \& A. Gary (Eds.), Community music therapy (pp. 35-47). England: Jessica Kingsley publishers.

Pavlicevic, M. (2003). Groups in Music, Strategies for Music Therapy. London: Jessica Kingsley Publishers.

Phillips, K. H. (2008). Exploring research in music education and music therapy. United States of America: Oxford university press.

Rickson, D.J. (2009). Community Music Therapy in New Music Therapy Communities. Voices: A World Forum for Music Therapy. Retrieved October 20, 2011, from http://testvoices.uib.no/?=colrickson230309

Rickson, D. J. (2010a). Managing Data: Thematic Analysis. Lecture notes, New Zealand School of Music, Wellington. 
Rickson, D. J. (2010b). The development of a music therapy school consultation protocol for students with high or very high special education needs. $\mathrm{PhD}$ thesis. Wellington, New Zealand: New Zealand School of Music.

Ruud, E. (2004). Community music therapy. [Discussion paper]. Retrieved on $18^{\text {th }}$ October 2011, from: www.hf.uio.no/imv/personer/vit/evenru/even.../CMTherapy.pdf Sacks, O. (1998). Music and the Brain. In C. M. Tmainno (Eds.), Clinical applications of music in neurologic rehabilitation (pp.1-18). Saint Louis: MMB Music Inc.

Seligman, M.E.P. (1975). Helplessness: on depression, development, and death. San Francisco: W. H. Freeman.

Stige, B. (2004). Performance of Community. Voices: A World Forum for Music Therapy. Retrieved October 19, 2011, from http://testvoices.uib.no/?q=fortnightlycolumns/2004-performance-community.

Stige B. (2010). Introduction, Music and Health in Community. In B.Stige. G, Ansdell. C, Elefant, \& M, Pavlicevic (Eds.), Where Music Helps, Community Music Therapy in Action and Reflection (pp. 3-16). UK: Ashgate.

Strauss, A., \& Corbin, J. (1990). Basics of Qualitative Research: Grounded Theory, Procedures and Techniques. Newbury Park: SAGE Publications.

Thaut, M.H., Gardiner, J.C., Holmberg, D., Horwits, J., Kent, L., Andrews, G., Donelan, B., \& McIntosh, G.R. (2009). Neurologic Music Therapy Improves Executive Function and Emotional Adjustment in Traumatic Brain Injury Rehabilitation. The Neurosciences and Music III-Disorders and Plasticity. 1169 (), 406-416

Warner, C. (2011). Music Therapy with Adults with Learning Difficulties and 'Severe Challenging Behaviour': An Action Research Inquiry into Group Music Therapy Within A Community Home. (Unpublished Post-Doctoral dissertation). The Music Therapy Charity. 
Wheeler, B.L. (1995). Music Therapy Research: Quantitative and Qualitative Perspectives. PA: Barcelona publishers.

Wheeler, B.L., Shultis, C.L., \& Polen, D. W. (2005). Clinical Training Guide for the Student Music Therapist. Gilsum NH: Barcelona Publishers.

Wong, E.H. (2004). Clinical Guide to Music Therapy in Adult Physical Rehabilitation Settings. United States of America: American Music Therapy Association Inc.

Wood, S. , Verney, S., \& Atkinson, J. (2004). From Therapy to Community: Making Music in Neurological Rehabilitation. In M. Pavlicevic \& A. Gary (Eds.), Community music therapy (pp. 48-64). England: Jessica Kingsley publishers.

Wood, S. (2006). "The Matrix": A Model of Community Music Therapy Processes. [online] Voices: A world Forum for Music Therapy, 6 (3).Retrieved on January, 2011 from https://normt.uib.no/index.php/voices/article/viewArticle/279/204

Yalom, I.D. (1985). The theory and practice of group psychotherapy $\left(4^{\text {th }} \mathrm{ed}\right.$.). New York: Basic Books. 


\section{Appendix 1 Advertisement to staff members}

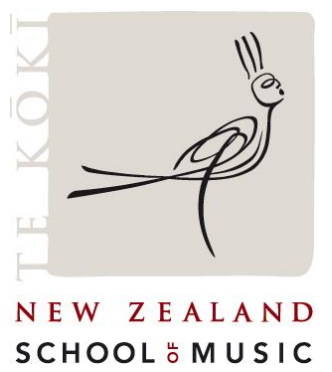

To staff members in rehabilitation centre:

I am going to do research about the use of music at the rehabilitation centre, and would really like your help.

I aim to use music to bring residents together and support their motivation and ability to work as a team, thus to improve the general milieu of a rehabilitation centre. I will use Action Research to improve my own learning and practice, and to describe outcomes that might be useful for rehabilitation and music therapy professionals.

The CEO of the rehabilitation centre has given permission for me to do research with the residents and the staff members.

If you agree to help me with my research, you will be interviewed twice, once in September, and once in October. Each interview will take one hour and will involve talking and reviewing the interview transcripts. I will talk to the CEO about whether the interviews can be carried out in your work time. Your name and the name of the centre will not be used in the research, and all other measures possible will be taken to protect your confidentiality.

If you would like to know the details about the research, please ask me for an information sheet. I would then be happy to talk to you about it.

Thanks,

Xinxin Liu 
Appendix 2: Information sheet for staff members

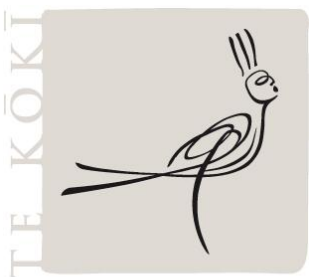

N E W Z E A L A N D

SCHOOL

\section{Information sheet for staff participants}

Research topic: Music therapy in a rehabilitation centre: improving the milieu using music?

Researcher: Xinxin Liu (Master student of Music Therapy)

\section{What is the research about?}

You are invited to take part in a project that will explore how music can enhance the general milieu in a rehabilitation centre. This research will aim to bring the residents together and help them work together in music. It is undertaken as part of a Master in Music Therapy under the supervision of Daphne Rickson, Music therapy lecturer/Coordinator of clinical programmes at the New Zealand School of Music.

\section{Who can be the participants?}

I will ask permission from CEO for the centre to be a research centre. Therefore all the residents $(n=24)$ and staff $(n=32)$ will be participants.

I will request informed consent to interview 2 staff members. I will ask all of the staff members and the first two who agreed to participate will be my interviewees.

\section{How is the research carried out?}

I will do action research. Action research will improve my learning and thinking, therefore improve my practice. I will ask you to give me feedback on my practice, so that I can further improve my learning and thinking, to make my practice better. My interactions will have an influence on you, and it is anticipated that you also might change your way of thinking and your way of acting. To improve the general milieu in a 
centre it would be important to start with what you think is appropriate, and then act according to that thinking.

I will interview 2 staff members. Each staff member will be interviewed twice: first time in September and second time in October. Each interview will take one hour and will involve talking and reviewing interview transcripts. You will therefore commit 2 hours in total for the research. Interviews will be semi-structured which means you will be guided to think about the topic but will not be asked too specific questions. I will ask your permission to audio record the interview, but you can ask me to turn it off at any time during the interview. I will write a transcript of the interviews and let you read and amend them before data has been used.

I will still be your colleague. I will critically analyse my thoughts so that my research improves my practice. My clinical work and research will be supervised separately by clinical supervisor and research supervisor.

\section{What will happen to the research data?}

Data will be stored at the facility in a locked cabinet. If the data is transferred to my home, I will keep it in a locked cabinet. The researcher, the researcher's supervisor, and a staff member at the facility (clinical liaison or CEO) are the only ones who can have access to the data during the research period. The raw data will be destroyed when study is finished. The processed data will be kept for 10 years in Massey University, and the researcher's supervisor will be responsible for their safe keeping. The processed data will be destroyed after 10 years.

\section{Is the research protecting my rights?}

If you decide to participate, you have the right to:

1) decline to answer any particular questions at any time;

2) withdraw from the research at any time during the research period from mid-August to late November;

3) ask any questions about the study at any time;

4) be referred to with a Pseudonym, and the centre will not be named. Real names will only be used if all participants, senior staff members and the CEO agree.

4) ask the researcher to provide a summary of the research when it is concluded. 
5) decide whether you want the interview be recorded

6) ask the researcher to turn off the recording device at anytime during the interview.

\section{What are the benefits for participating in the research?}

I am improving my own thinking and practice through the research, so that residents will get better. The findings will be useful for the centre, and other rehabilitation and music therapy communities.

\section{What are the risks for participating in the research?}

The physical and psychological risks would be minimal. However, usual health and safety protocol within the facility where the interview is taken place will apply to this research.

\section{Statement of approval.}

This project has been reviewed and approved by the Massey University Human Ethics Committee: Southern A, Application 10/53. If you have any concerns about the conduct of this research, please contact Professor Julie Boddy, Chair, Massey University Human Ethics Committee: Southern A, telephone 063505799 ext 2541, email humanethicsoutha@massey.ac.nz

Please spend minimum two weeks to think and to talk with managers or friends about my invitation. If you decide to participate you can change your mind at any time.

If you have any questions about this research you contact me at:

Xinxin.liu1@gmail.com or my supervisor: Daphne Rickson, Music Therapy Lecturer, New Zealand School of Music, P.O. Box 2332, Wellington, Ph: 048015799 x6979, email Daphne.Rickson@nzsm.ac.nz. 


\section{Appendix 3: Consent form for staff members}

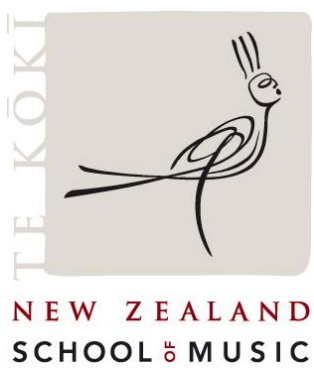

\section{Consent form for staff participating in the interview}

Research title: the use of music therapy to enhance the general milieu in a rehabilitation centre.

I have read the information sheet dated for volunteers taking part in the research: Music therapy and rehabilitation centre: how to improve the milieu using music?

I have had this research explained to me by

My questions have been answered to my satisfaction, and I understand that I may ask further questions at any time.

I understand that I have the right to choose to participate in the study. I also have the right to withdraw from the study at any time.

I understand that my participation in this study is confidential. Information that can identify me will not be used in any reports on this research, unless all parties request to be named.

I understand the interview will be stopped if it should appear harmful to me.

I have had time to consider whether to take part in this research.

I know who to contact if I have any questions about the research.

I wish to receive a copy of the summary of the study. Yes / No (please circle) 
I consent to my interview being audio recorded (by an MP3). Yes / No (please circle)

I wish to have my sound recordings returned to me. Yes / No (please circle)

I agree to participate in this study under the conditions set out in the information sheet.

I (full name) hereby consent to take part in this study.

Date:

Signature: 


\section{Appendix 4: Interview guideline for staff interviewees}

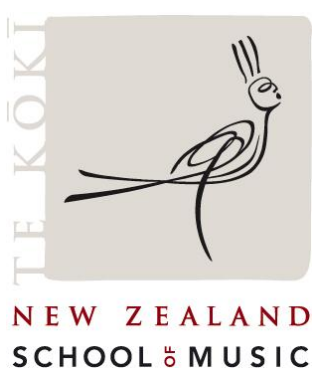

Action research is iterative, so the action initiates change, and the change further influence the further action. Therefore specific questions and interview cannot be prepared beforehand. However interview questions and questionnaires can be based around themes and verbal prompts will be used.

First staff interview Guidelines:

1. Can you tell me something about residents' music listening habits?

2. Can you tell me about any music making that you have observed the residents engaged in?

3. How do you think the preparation for the concert is going?

4. Can you tell me something about the way in which the residents interact in their free time?

5. How would you describe the general milieu of the centre?

6. Is there anything else you would like to discuss regards to the music therapy service?

Second staff interview Guidelines:

1. What do you think about the concerts?

2. What do you think about listening to CDs at lunch time?

3. Did you have any response to the lunch time music?

4. Did you observe any interactions during the concert?

5. Did you observe any interactions among residents and/or staff members before or after the concert?

6. Did you observe any interaction related to lunch time music? 


\section{Appendix 5: Information sheet for residents}

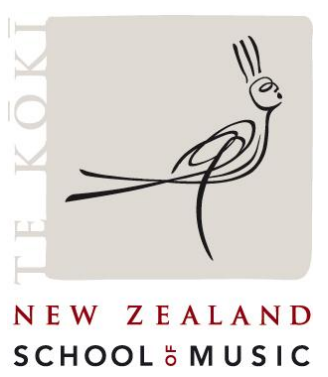

\section{Information sheet for resident participants}

\section{Music therapy in a rehabilitation centre: improving the milieu using music? Researcher: Xinxin Liu (Master student of Music Therapy)}

As you know I have been doing music in the rehabilitation centre. I will continue to do music here until the end of November. I want to do research about how the music affects us in the centre, which helps me to improve my work. This would also be good for the residents in the centre, and would help other music therapists to know my work.

I will talk to you about music in the centre for my research. I would like to use a MP3 to record our conversations. You can ask me to turn it off at any time. You do not have to answer all my questions if you don't want to. Then we go through the checking process. After I write down what I recorded in the MP3 you will review it with me and change things that you are not happy with.

The conversation and reviewing process will occur twice, first time in September and second time in October, and each will take 1 hour.

I will invite 23 other people from the centre to talk to me, but I can only talk to the first 3 people who sign the consent paper. I would let you know if you were chosen or not.

You will be able to do music with me as usual, whether you want to talk to me or not. The research will not interfere with our usual music sessions. If you are having individual sessions or group music sessions with me, you can still have these music 
sessions. Staff members at LFT are interested in how music can help people work together. Therefore I will try to encourage you to think if you want to play music outside the music sessions. If you are learning to play the keyboard, you might like to join other people to make a music group or a band. If you are listening to CDs with me, you might like to share the CDs with other residents. These types of sessions might change due to your needs or your time table changes. This is usual practice, and the change will be discussed with CEO or manager of the rehabilitation centre.

My research will contribute towards my Master of Music Therapy degree. The work will be published and will be available in the University library. It will not have your real name or the name of the centre in it. You will be given a summary of the research if you would like one.

All the recordings and other documents will be stored at the University for 10 years after the research finished. After that they will be destroyed.

This project has been reviewed and approved by the Massey University Human Ethics Committee: Southern A, Application 10/53. If you have any concerns about the conduct of this research, please contact Professor Julie Boddy, Chair, Massey University Human Ethics Committee: Southern A, telephone 063505799 ext 2541, email humanethicsoutha@massey.ac.nz

Please take at least two weeks to think and to talk with staff or friends about my invitation. After you decide to get involved you still can change your mind at any time.

If you have any questions about this research please feel free to contact me:

Xinxin.liu1@gmail.com

or my supervisor: Daphne Rickson, Music Therapy Lecturer, New Zealand School of Music, P.O. Box 2332, Wellington, Ph: 048015799 x6979, email

Daphne.Rickson@nzsm.ac.nz.

Xinxin Liu

Researcher, Master of Music Therapy Student 


\section{Appendix 6: Consent form for residents}

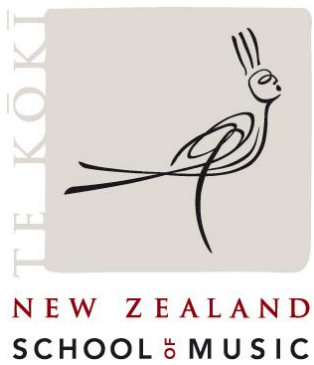

\section{Consent form for residents participating in the research}

Research title: the use of music therapy to enhance the general milieu in a rehabilitation centre.

I have read the information sheet dated for volunteers taking part in the research: Music therapy and rehabilitation centre: how to improve the milieu using music?

I have had this research explained to me by . I have asked questions about the study and I am satisfied with the answers. I understand I can ask further questions at any time.

I understand that Xinxin will be interviewing me about music in the centre. I understand that I have the right to choose to talk to her. I also have the right to change my mind anytime. If I do chose not to talk to her in the interview, or change my mind, I will still have usual music therapy.

I understand that Xinxin will record the interview with her MP3. I understand I can ask her to switch it of any time during the interview.

I understand that my participation in this study is confidential. My name and the name of the centre will not be used in this research, unless everybody agreed to use our names.

I understand if the interview will cause me any discomfort, it will be stopped.

I have had time to consider if I want to take part in this research. 
I know who to contact if I have any questions about the research.

I wish to receive a copy of the summary of the study. Yes/No (please circle)

I consent to my interview to be recorded by MP3. Yes / No (please circle)

I wish to have my sound recordings returned to me. Yes / No (please circle)

I agree to participate in this study under the conditions set out in the information sheet.

I (full name) hereby consent to take part in this study.

Date:

Signature:

For further information, please contact:

Research supervisor: Daphne Rickson, Music Therapy Lecturer, New Zealand School of Music, P. O. Box 2332, Wellington, Ph: $04 \quad 8015799$ x6979, email Daphne.Rickson@nzsm.ac.nz

Researcher: Xinxin Liu, Master of Music Therapy student, xinxin.liu@ gmail.com 


\section{Appendix 7: Interview guidelines for resident interviewees}

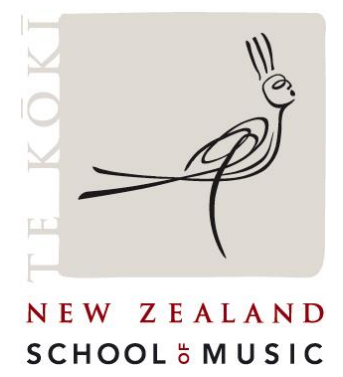

Action research is iterative, so the action initiates change, and the change further influence the further action. Therefore specific questions and interview cannot be prepared beforehand. However interview questions and questionnaires can be based around themes and verbal prompts will be used.

First Residents Interview Guidelines:

1. Have you been listening to music?

2. Do you listen to music by yourself or with other people?

3. Have you been playing or singing by yourself?

4. Have you been playing or singing with other people?

5. What do you think about the music that has been happening in the centre since the music therapy student has been here?

6. Tell me about what it is like preparing for the concert?

7. Thinking mostly about the music that happens here, can you describe what it is like living with other people?

8. Is there anything you can suggest to improve the milieu of the centre?

9. Is there anything you like to discuss regards to the music therapy service?

Second Residents Interview Guidelines:

7. What do you think about the concerts?

8. What do you think about listening to CDs at lunch time?

9. Did you observe any interactions during the concert?

10. Did you observe any interactions before or after the concert?

11. Did you observe any interaction related to $\mathrm{CD}$ listening?

12. What do you think about the music in Travel the World group?

13. What do you think about the musical games? 


\section{Appendix 8: Authority for the release of transcripts form for staff and resident}

interviewees

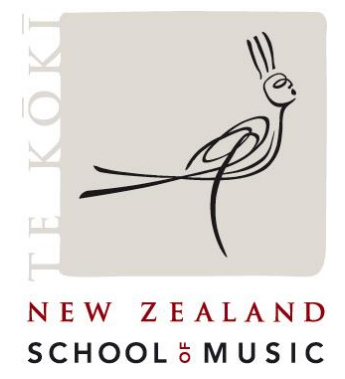

Authority for the release of transcripts

Project title: The use of music therapy to enhance the general milieu in a rehabilitation centre:

I confirm that I have had the opportunity to read and amend the transcript of the interview(s) conducted with me.

I agree that the edited transcript and extracts from this may be used in reports and publications arising from the research.

Signature

Date:

Full-name (print)

If you have any questions about this research you can ask me: Xinxin.liu1@gmail.com or my supervisor: Daphne Rickson, Music Therapy Lecturer, New Zealand School of Music, P.O. Box 2332, Wellington, Ph: $04 \quad 8015799$ x6979, email Daphne.Rickson@nzsm.ac.nz. 


\section{Appendix 9: Example of Observation and Reflection}

In this research, I observed what happened, and reflect on why that happened, what was I thinking when it happened, and what I should improve.

For example, In Cycle One: Preparation for ECC Concert, I wrote in my observation: The residents who attended the first concert showed interest in coming to the ECC concert. Julie and Jacob both told me that they wanted to be part of the concert and put some effort to it, and they will look for songs. Lily suggested Eternal flame, which was hard for the residents to sing. Jacob said he would bring his CD but he didn't. Jacob suggested a song 'Turn On The Sun' which was easy for the residents to prepare.

I reflected on what I did, and questioned myself: why did I do it? I wrote the following in my self-reflective journals:

"hard", and "easy":

who decided the songs were hard or easy? How did I know if it was hard or easy? Why did I care if it was hard or easy?

--I decided the song was hard or easy.

--I knew the songs were hard or easy base on my music knowledge

--or simply because I'm more familiar with the songs

--Why we need to sing easy songs?

--So the residents can improve their confidence through singing the songs.

--So it is easier for me to prepare!

Based on my reflection, I planned what I will do next. For example, I wrote:

I should choose the songs that are relatively easy for the residents to prepare, but I should also let the residents to choose the songs they want to sing.

In Cycle Two, I wrote:

The songs were probably too easy for the residents, and they felt lack of motivation to practice. 


\section{Appendix: 10: Examples of Interview Transcripts}

These were the sections from the first interviews.

Transcript from interviewing resident Iris:

Xinxin: So have you heard of the residents talking about the music making process or the music?

Iris: Yes I have. They quite often say to me: you should have joined because it's an interesting experience. Yeah. But at the time Xinxin started, I was doing something else and I couldn't join.

Transcript from interviewing staff Abby:

Xinxin: Do you observe any changes when the music therapy student has come here, the way the residents interact?

Abby: Well, there is conversation about the choice they are talking on, whether It's choice of the song or the choice of instruments. It's good because it's movement, whether it's vocal cords or with the limbs. And it's time structured. When they got an appointment, there is a time and a place, you know, it's a job. The job you have to be there on time, and you put into practice what you already knew, or lean what you don't. 


\section{Appendix 11: Examples of analyzing Observation and Reflection}

The observation and reflection were analysed through Thematic Analysis. First I named codes, and I grouped common codes together to generate Categories. I used the Coding Paradigm model to help me to code the data into Categories.

For example, in the Cycle Four of learning:

\section{The observation was:}

However, Lily suggested that the songs the residents chose were probably too difficult to sing. I asked if the residents still wanted to sing these songs. One resident said, we should still sing 'I saw mommy kissing Santa Clause”, because another resident Julie would love it. The other residents however agreed to Lily, and said this song would be difficult to sing. The group therefore decided to follow Lily's idea, and sing other Christmas Carols that were easier, such as "Jingle Bells".

\section{One of the Events was:}

Residents decided songs to sing for the Pre-Christmas concert, including 'I saw Mommy kissing Santa Clause'. However, the group decided to sing easier songs later.

\section{The Reason was:}

One resident Lily suggested singing easier song, after the decision was made.

\section{The Context was:}

In previous concerts: First concert and the ECC concert, we sang easy songs. The residents seemed uncertain about singing the song 'I saw Mommy kissing Santa Claus'. I didn't know the song well, so I couldn't give the residents a clear picture of how the song was going to be like.

\section{The Intervening Condition was:}

I suggested the residents to sing our version of the song, alternatively we could sing the chorus part of the songs. 


\section{The Interaction / Action were:}

One resident Lucy mentioned to us: Julie liked this song, she might be happy if we sing this song in the concert.

Other residents said to sing 'I saw Mommy kissing Santa Claus'; they had to sing in very high pitch. They felt awkward to mimic the kissing sound in the song.

\section{The Consequence was:}

The group decided to sing the easier Christmas Carols.

\section{The Category was:}

\section{Group Consensus}

When making decision through group consensus, the majority members makes decision, and the minority group member's idea was lost.

\section{My action}

Reflect back on my action in the first cycle of learning: I decided the residents should sing easy songs in the ECC concert.

My action in the previous concerts probably affected the residents' behavior in Cycle four: the residents might have thought that they can only sing songs at the "easy" level. 


\section{Appendix 12: Examples of analyzing Interview Transcripts}

The interviews were analysed through Thematic Analysis. First I named codes, and I grouped common codes together to generate Categories.

This is a section of the first interview with resident Iris

Xinxin: So have you heard of the residents talking about the music making process or the music?

Iris: Yes I have. They quite often say to me: you should have joined because it's an interesting experience. Yeah. But at the time Xinxin started, I was doing something else and I couldn't join.

From this transcript, I identified two codes:

Residents encouraged each other to join the music therapy session. Residents enjoyed the music therapy sessions.

This is a section from the first interview with staff member Abby

Xinxin: Do you observe any changes when the music therapy student has come here, the way the residents interact?

Abby: Well, there is conversation about the choice they are talking on, whether It's choice of the song or the choice of instruments. It's good because it's movement, whether it's vocal cords or with the limbs. And it's time structured. When they got an appointment, there is a time and a place, you know, it's a job. The job you have to be there on time, and you put into practice what you already knew, or lean what you don't.

From this transcript, I identified several codes:

Residents talk about music therapy sessions

Residents had choice of musical activities in the music therapy sessions

Music therapy sessions is beneficial for rehabilitation

Attending the sessions is a responsibility 
I found the common codes in the two interview transcript:

Iris: residents invite each other

Abby: residents talk about the sessions

I grouped the codes together to form a category, and I named this category:

Music Therapy sessions encourage communication

I described the category:

Residents talked to each other about the sessions, and encouraged each other to join. 